\author{
Economics Working Paper Series
}

\author{
2015/031
}

\title{
Dynamic Effects of Monetary Policy Shocks on Macroeconomic Volatility
}

\author{
Haroon Mumtaz and Konstantinos Theodoridis \\ The Department of Economics \\ Lancaster University Management School \\ Lancaster LA1 4YX \\ UK
}

(C) Authors

All rights reserved. Short sections of text, not to exceed two paragraphs, may be quoted without explicit permission, provided that full acknowledgement is given. 


\title{
Dynamic Effects of Monetary Policy Shocks on Macroeconomic Volatility*
}

\author{
Haroon Mumtaz ${ }^{\dagger}$ \\ Queen Mary University of London \\ Konstantinos Theodoridis $\ddagger$ \\ Bank of England \& Lancaster University Management School
}

December 1, 2015

\begin{abstract}
We use a simple New Keynesian model, with firm specific capital, non-zero steady-state inflation, long-run risks and Epstein-Zin preferences to study the volatility implications of a monetary policy shock. An unexpected increase in the policy rate by 150 basis points causes output and inflation volatility to rise around $10 \%$ above their steady-state standard deviations. VAR based empirical results support the model implications that contractionary shocks increase volatility. The volatility effects of the shock are driven by agents' concern about the (in) ability of the monetary authority to reverse deviations from the policy rule and the results are re-enforced by the presence of non-zero trend inflation.
\end{abstract}

Keywords: DSGE, Non-Linear SVAR, New Keynesian, Non-Zero Steady State Inflation, Epstein-Zin preferences, Stochastic Volatility

JEL Classification: E30, E40, E52, C11, C13, C15, C50

*The views expressed in this paper are those of the authors, and not necessarily those of the Bank of England. We would like to thank Ferre De Graeve, Riccardo Masolo and Ricardo Reis for helpful discussions and comments.

${ }^{\dagger}$ Email: h.mumtaz@qmul.ac.uk

${ }_{\ddagger}^{\ddagger}$ Email: konstantinos.theodoridis@bankofengland.co.uk 


\section{Introduction}

Monetary authorities around the industrialised world are responsible for country's price, growth, employment and financial stability. They aim to meet the objectives set by the society via their instruments. This suggests that their actions have a first order effect on agents' economic behaviour. For instance, monetary authorities are able to alter households' and firms' consumption, investment and pricing plans by adjusting the policy rate. The transmission of monetary policy actions to the economy and their first order effects are well studied by the monetary economics literature. However, the volatility implications - second order effects - induced by these actions have received less attention.

The question that arises naturally is "do we need to be concerned about the volatility effects of monetary policy shocks?". A number of recent events suggest that the answer to this question is yes. For example, the "taper tantrum" in June 2013 was associated with an increase in speculation that the Federal Reserve would start on a tapered end to QE in 2014. This discussion increased financial market volatility, pushed up long-term interest rates and induced heavy losses on bond investors. These anecdotal observations are further supported by empirical results present below. Using a structural VAR with stochastic volatility (extended to allow for feedback from the endogenous variables to the volatility), we show that monetary policy shocks increase macroeconomic volatility and the results are robust across identification schemes.

To understand how volatility is affected when monetary authorities decide to deviate unexpectedly from their Taylor type reaction function, we employ a stylised New Keynesian DSGE model, with firm specific capital, non-zero steady-state inflation, long-run risks and Epstein-Zin preferences. The model has been calibrated to match successfully a set of macroeconomic and financial moments.

Simulations from the theoretical model suggest that the transmission of the policy shock to volatility depends on three model parameters: the interest rate policy smoothing, the EpteinZin risk and the steady-state inflation parameters. The policy rate smoothing parameter is what causes the monetary policy to have economically significant volatility effects and not the shock per se. In other words, the agents are not that much concerned that authorities are able to deviate unexpectedly form their objective function but they price significantly the fact that they cannot fully undo such actions. When the economy is at its steady-state, then an expected increase increase of the policy rate is interpreted as a 'mistake' as it represents a deviation from the Taylor rule and causes inflation and output growth to deviate form target values. Authorities try from the second period onwards to correct their mistake by cutting the policy rate but they can only do so partly due to their smoothing preferences. Consistent with the analysis of Rudebusch and Swanson (2012) and Swanson (2015), the Epstein-Zin risk parameter alters the size of these second order effects. Finally, the non-zero steady-state inflation parameter induces a trade off between nominal and real volatility. As the steadystate inflation increases the slope of the Phillips curve becomes flatter (see for instance, Ascari 
and Sbordone (2014) and King and Wolman (1999)) and this reflects firms' elevated concerns about expected inflation that erodes their average markup. As the demand decreases after a contractionary monetary policy shock, firms find it optimal to reduce their prices. However, they also realise that inflation trends and, due to Calvo pricing contracts, they may become stuck with the current price for some time. At the same time because the Phillips curve is flatter the monetary authorities become less effective in restoring inflation back to its target and this causes the long-term interest rate to be lower for longer, which ends up stimulating output a year after the shock. This elevated demand is what mitigates households's concerns about output.

The analysis presented here goes some way in explaining why authorities have been extremely cautious about when to initiate monetary policy normalisation as they may not be able to undo their actions quickly. The role played by steady state inflation in the model indicates that calls to raise the inflation target (see Blanchard et al. $(2010)$ ) as a counter to the zero lower bound (ZLB) may be misplaced. As in Coibion et al. (2012) and Ascari et al. (2015) our study highlights the nominal risks of raising the inflation target in an environment where firms set price based on Calvo schemes and monetary authorities set policy based on a Taylor rule reaction function.

As in empirical and theoretical literature on the impact of uncertainty shocks (Bloom $(\overline{2009})$, Fernandez-Villaverde et al. (2011), Mumtaz and Zanetti (2013), Born and Pfeifer (2014), Mumtaz and Theodoridis (2015) and Fernandez-Villaverde et al. (forthcoming)), our paper highlights the importance of these type of disturbances. However, the focus and results of our analysis are novel in one key respect. Unlike the bulk of the uncertainty literature, this paper attempts to model the transmission of monetary policy shocks to economic volatility and thus takes a step towards treating economic volatility as endogenous.

The papers closest to our work are the studies of Rudebusch and Swanson (2012) and Swanson (2015), who use a very similar theoretical setup to the one employed here to understand the asset pricing implications of volatility effects caused by level shocks. Our paper is also related to the work of Bikbov and Chernov (2013), Song (2014) and Campbell et al. (2014), who uses macro-finance models to understand the relationships between monetary policy and bond risk premia. Finally, our study is related to the literature that investigates the macroeconomic implications of non-zero steady-state inflation (Cogley and Sbordone (2008), Ascari and Rossi (2012) and Ascari and Sbordone (2014)).

The paper is organised as follows, Section 2 presents the empirical model and discusses the data and empirical results. Section 3 reviews the theoretical model, its calibration and presents the impulse response analysis. The final section concludes. 


\section{Empirical Analysis}

In this section we present results from a simple econometric model that show strong evidence that contractionary monetary policy shocks result in an increase in macroeconomic volatility.

\subsection{Empirical Model}

In order to estimate the impact of monetary policy shocks on second moments of key macroeconomic variables, we estimate an extended structural VAR model with stochastic volatility:

$$
Z_{t}=c+\sum_{j=1}^{P} \beta_{j} Z_{t-j}+\Omega_{t}^{1 / 2} e_{t}, e_{t} \sim N(0,1)
$$

where

$$
\Omega_{t}=A^{-1} H_{t} A^{-1^{\prime}}
$$

In equation (1) $Z_{t}$ denotes the $N=4$ macroeconomic variables described below. The matrix $H_{t}$ holds the volatility of the orthogonalised shocks on the main diagonal

$$
H_{t}=\operatorname{diag}\left(\left[\exp \left(h_{1, t}\right), \exp \left(h_{2, t}\right), . ., \exp \left(h_{N, t}\right)\right]\right)
$$

The structure of the $A$ matrix is chosen by the econometrician to model the contemporaneous relationship amongst the reduced-form shocks. We discuss our choice of the structure of the $A$ matrix in section 2.4 below.

The transition equation for the stochastic volatilities is given by the following VAR model:

$$
\tilde{h}_{t}=\alpha+\theta \tilde{h}_{t-1}+\sum_{j=1}^{K} d_{j} Z_{t-j}+\eta_{t}, \eta_{t} \sim N(0, Q), E\left(e_{t}, \eta_{t}\right)=0
$$

$\tilde{h}_{t}$ denotes a matrix that holds the log variances $h_{1, t}, h_{2, t}, . . h_{N, t}$. The VAR constants and coefficients on lags are denoted by $\alpha$ and $\theta$, respectively. The coefficients $d_{j}$ allow lagged endogenous variables to affect the log variances. If these coefficients are non-zero, then shocks to equation (1) have an impact on $\tilde{h}_{t}$ and consequently on $\Omega_{t}$ and measures of the unconditional variance of $Z_{t}$.

The model in Equations (1) and (3) contains two innovations relative to the standard BVAR with stochastic volatility (see Clark (2011)). First, it allows the elements of $\tilde{h}_{t}$ to co-move while most of the previous literature assumes an independent AR or random walk process for each log variance. The specification used here thus captures the possibility that volatility of shocks 
to macroeconomic and financial variables may move together - a phenomenon that may be important during periods of recession and financial stress.

Secondly, unlike previous applications of this model, the addition of the term $\sum_{j=1}^{K} d_{j} Z_{t-j}$ in equation (3) allows us to investigate the impact of structural shocks on the volatility of the endogenous variables 1 The model thus accounts for the possibility that the variance of output, inflation and financial variables may be affected by innovations that have an impact of the level of these variables. As discussed above, our interest lies in investigating the possible impact of monetary policy shocks on the second moments of the endogenous variables. The specification above enables us to calculate the impulse response of $\operatorname{var}\left(Z_{t}\right)$ to a monetary policy shock identified via an appropriate structure for $A$.

The benchmark model makes the simplifying assumption that $\tilde{h}_{t}$ does not have a feedback effect on the endogenous variables (see Mumtaz and Theodoridis (2015), Mumtaz and Surico (2013) and Mumtaz and Zanetti (2013) for example). This assumption reduces the number of unobserved state variables in the model and simplifies the estimation algorithm. We show in the sensitivity analysis that an extended model that allows for this feedback produces very similar impulse responses and this assumption appears innocuous in our application.

\subsection{Data}

The model is estimated using US data on the monthly growth rate of industrial production, monthly CPI inflation, the three month T-bill rate and the spread of 10 year government bonds over the three month T-bill rate. The data is monthly and runs from $1947 \mathrm{~m} 1$ to $2007 \mathrm{~m} 12$, with the last few years dropped as they represent the period of unconventional monetary policy. The data on industrial production, CPI and the three month T-Bill rate is obtained from FRED, while the long term bond yield is obtained from Global Financial Data.

\subsection{Estimation and impulse responses}

The model is estimated using Bayesian methods. In the on-line appendix we state in detail the Gibbs sampling algorithm used to approximate the posterior distribution. In short, the algorithm is a simple extension of the MCMC methods used to estimate Bayesian VARs with stochastic volatility, presented for example in Cogley and Sargent (2005a). The prior distribution for the VAR coefficients in equation (1) are based on existing studies and 'shrink' the VAR coefficient matrix towards an AR specification for each endogenous variable. We employ a similar prior for the transition equation and thus assume apriori that each log stochastic volatility follows an AR process and that there is no feedback from $Z_{t-j}$.

\footnotetext{
${ }^{1}$ An exception is the univariate stochastic volatility in mean model of Chan $(0)$ that allows lagged effects from the data in the transition equation.
} 
The impulse responses of log $\operatorname{var}\left(Z_{t}\right)$ to a monetary policy shock are calculated via MonteCarlo integration ${ }^{2}$ In particular, the impulse responses are defined as the difference between the following conditional expectations

$$
I R F_{t}=E\left(\ln \operatorname{var}\left(Z_{t+k}\right) \backslash \Psi_{t}, Z_{t-1}, \mu\right)-E\left(\ln \operatorname{var}\left(Z_{t+k}\right) \backslash \Psi_{t}, Z_{t-1}\right)
$$

where $\Psi_{t}$ denotes the parameters and state variables of the model and $\mu$ is the monetary policy shock. The first term in equation (4) denotes a forecast of the log volatility conditioned on one of the structural shocks $\mu$. Note that, the volatility of the endogenous variables depends on the structural shocks through equation (3) above. The second term is the baseline forecast of the log variance, i.e. conditioned on the scenario where the shock equals zero. Koop et al. (1996) describe how to approximate these conditional expectations via a stochastic simulation of the non-linear VAR model. We use 100 simulations to calculate $I R F_{t}$ repeating this for 500 retained Gibbs draws. In order to account for history dependence of the non-linear responses, the calculation is done for $t=1,12, \ldots T$ i.e. every $12^{t h}$ month in the sample and the mean across time is reported in the figures below.

\subsection{Model specification and identification}

We set the lag length in the VAR model to 12 and use 3 lags of the endogenous variables in the transition equation (3). As shown in the sensitivity analysis, the main results are very similar for longer lag lengths.

We consider three schemes to identify the monetary policy shock. The benchmark identification scheme uses contemporaneous sign restrictions to identify the monetary policy shock. We assume that a contractionary policy shock increases the short-term interest rate on impact and leads to a fall in industrial production growth and CPI inflation. The second scheme assumes a recursive structure and implies that monetary policy shocks have no contemporaneous impact on output and inflation but can affect the term spread immediately. Finally, we use the cumulated Romer and Romer (2004) index as a proxy for monetary policy shocks and include it in the VAR model in place of the short-term interest rate and estimate the responses using the same recursive structure as in the previous scheme.

\subsection{Results}

Figure 1 presents the impulse response to a contractionary monetary policy shock normalised to increase the T-Bill rate by 100 basis points. The monthly growth rate of industrial production declines by $0.5 \%$ on impact an recovers within 2 months. The term spread decline by about 70 basis points on impact suggesting that the long term rate rises by about 30 basis points

\footnotetext{
${ }^{2}$ We focus on the $\log$ of the variance as this proved to be more numerically stable than the level.
} 


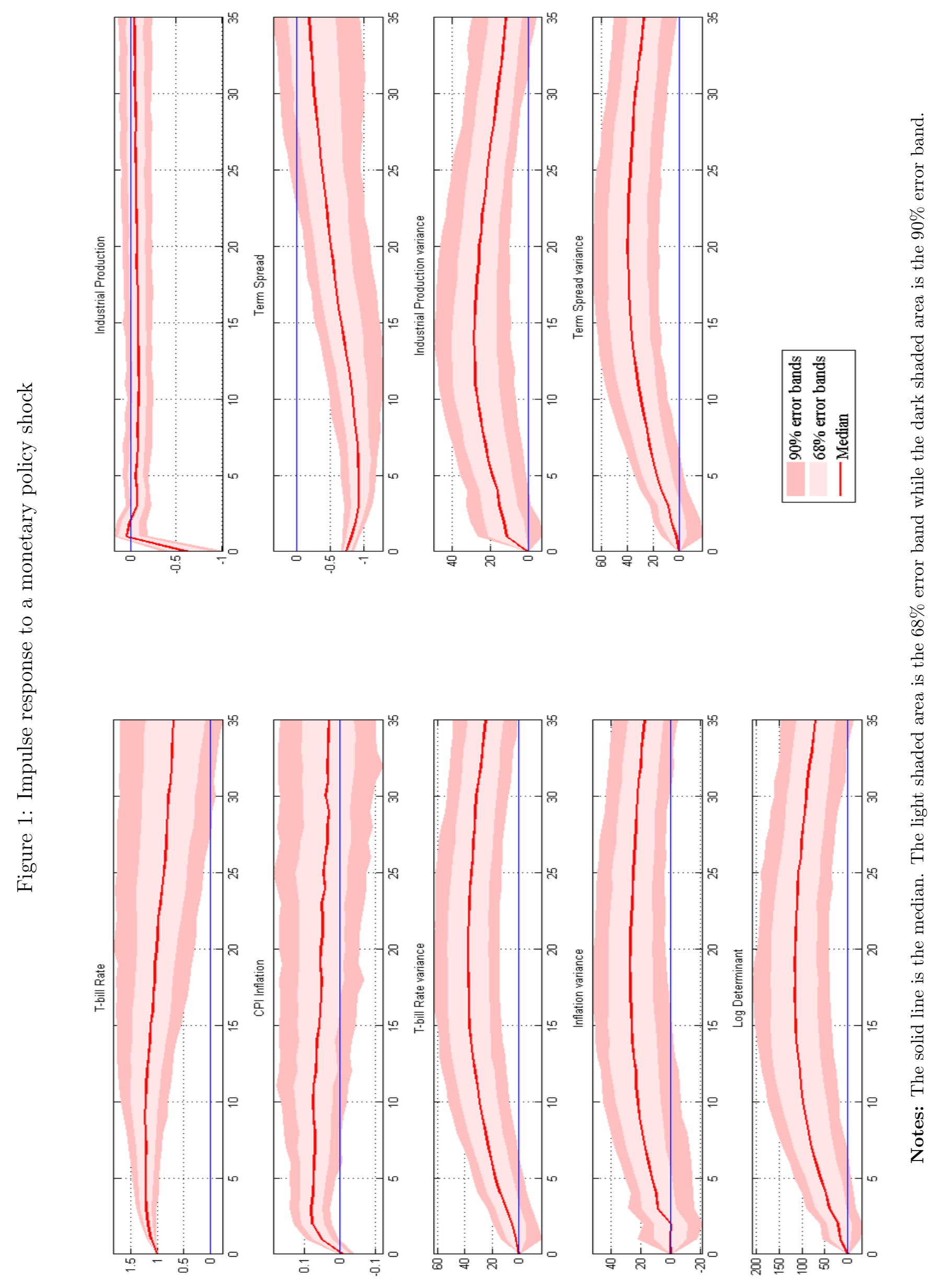


in response to monetary contraction. The response of inflation is characterised by the price puzzle with inflation rising beyond the impact period before returning to base in about two years. This positive response of inflation is common across all the identification schemes we employ and is consistent with the view expressed in recent papers that this is a feature of the data in the pre-Volcker period (see Castelnuovo and Surico (2010)).

The last three rows of the figure present the response of the unconditional volatility to this shock. It is clear from the figure that the volatility of all endogenous variables rises in response to this shock. This is reflected in the measure of overall volatility, the log determinant of the covariance matrix of the endogenous variables which shows a persistent increase $3^{3}$ The response of volatility is persistent lasting for about 2.5 to 3 years with the magnitude of the response of the interest rates somewhat larger than the macroeconomic variables.

Figure 2 presents the response of the volatility of the endogenous variables estimated using the three identification schemes discussed above. The figure shows the two alternative identification schemes also suggest that the log volatility of all variables increases after a monetary contraction. The on-line appendix shows that the same results are obtained if the specification of the model is changed. For example, the same results are obtained from an extended model that allows feedback from the stochastic volatilities to the endogenous variables. Finally, the results remain the same if industrial production is replaced by the unemployment rate or if a stock market index is introduced into the model.

To summarise, the empirical analysis suggests that contractionary monetary policy shocks result in an increase in the variance of output, inflation and financial variables such as interest rates and the term spread. In the next section we build a DSGE model to explain the transmission of the monetary policy shock into second moments of these variables.

\section{Theoretical Analysis}

\subsection{DSGE Model}

The model used in this section is very similar to the one developed by Rudebusch and Swanson (2012). In this section we describe the building blocks of the key sectors of the model.

Households: The economy is populated by a continuum of households $(h \in[0,1])$ that attain utility from consumption $\tilde{C}_{t}(h)$ and leisure $1-L_{t}(h)$. Household's preference preferences are separable

$$
u\left(\tilde{C}_{t}(h), \tilde{Z}_{t}, L_{t}(h)\right)=\frac{\tilde{C}_{t}(h)^{1-\sigma_{C}}}{1-\sigma_{C}}-\chi_{0} \tilde{Z}_{t}^{1-\sigma_{C}} \frac{L_{t}(h)^{1+\sigma_{L}}}{1+\sigma_{L}}
$$

\footnotetext{
${ }^{3}$ This measure of overall volatility is attributed to WILKS (1932) and Whittle (1953).
} 

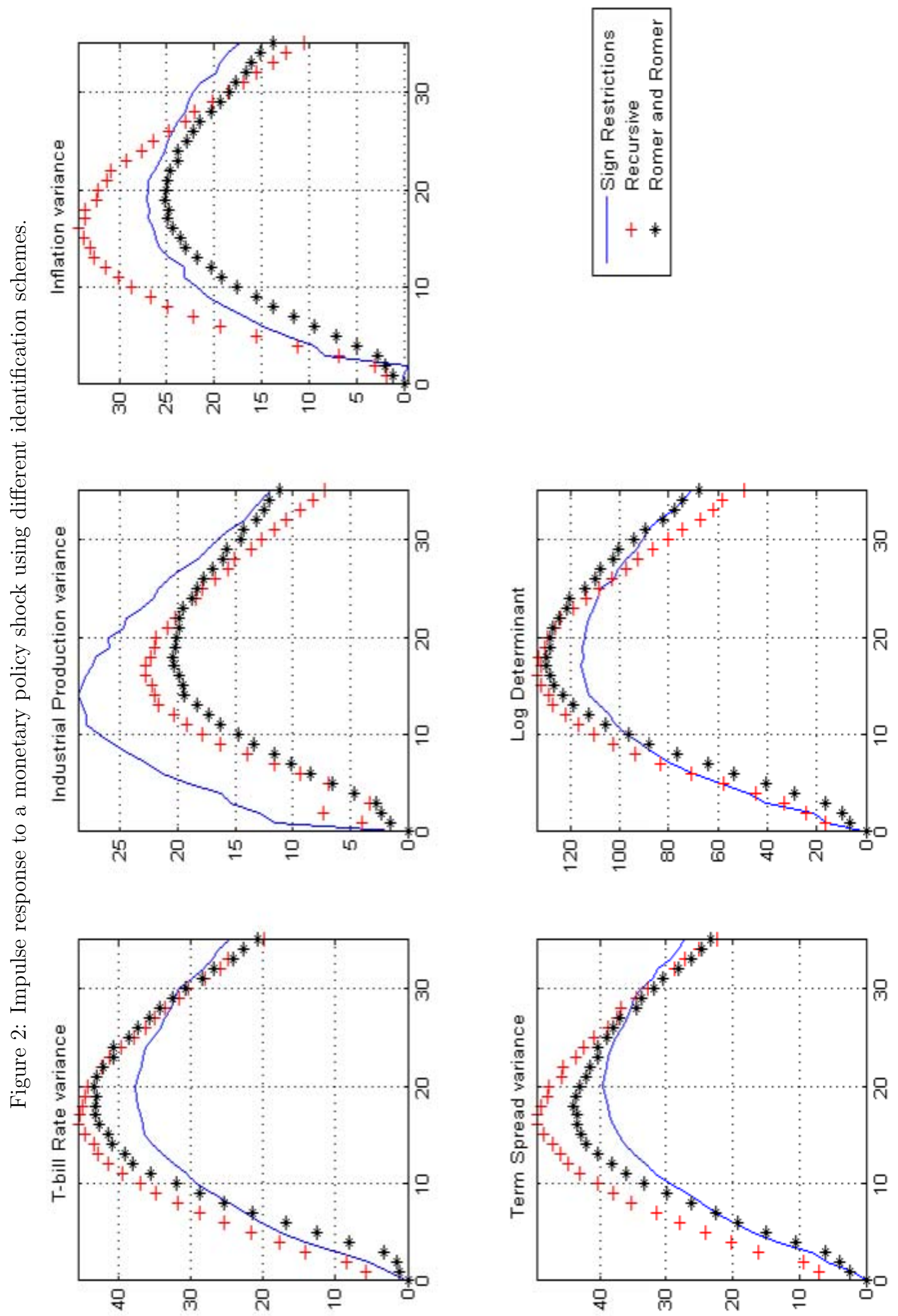
where $\sigma_{L}$ is the inverse of the Frisch elasticity, $\sigma_{C}$ stands for the inverse of intertemporal elasticity of substitution and $\tilde{Z}_{t}$ denotes the non-stationary productivity process (the tilde indicates that the variable is non-stationary)

$$
Z_{t}=\frac{\tilde{Z}_{t}}{\tilde{Z}_{t-1}}=Z\left(Z_{t-1}\right)^{\rho_{z}} e^{\sigma_{z} \omega_{z, t}}
$$

where $z$ is the steady-state value of the productivity growth, $\rho_{z}$ indicates the degree of persistence and $\sigma_{z}$ is the standard deviation of the productivity process. Furthermore, households have recursive preferences (Epstein and Zin (1989), Weil (1989, 1990)

$$
V_{t}(h)=u\left(\tilde{C}_{t}(h), \tilde{Z}_{t}, L_{t}(h)\right)+\beta\left(E_{t} V_{t+1}(h)^{1-\gamma}\right)^{\frac{1}{1-\gamma}}
$$

The attractive feature of Epstein-Zin preferences is that the coefficient of relative risk aversion decouples from the intertemporal elasticity parameter. The parameter $\gamma$ illustrates the degree of agents' desire for an early resolution of uncertainty over future consumption. Household maximises its utility function subject to its budget constraint is

$$
\tilde{P}_{t} \tilde{C}_{t}(h)+\frac{\tilde{D}_{t}(h)}{R_{t}}+T_{t}(h)=\tilde{P}_{t} \tilde{W}_{t} L_{t}(h)+\tilde{D}_{t-1}(h)+\Xi_{t}(h)
$$

where $\tilde{P}_{t}$ is the price index, $\tilde{D}_{t}(h)$ is the one period risk free government debt, $R_{t}$ is the return on investing on the government debt, $\tilde{W}_{t}$ stands for the real wage, $T_{t}(h)$ is the lump sum taxes and $\Xi_{t}(h)$ denotes firms' profits. This optimisation problem delivers (after some substitutions) the labour supply

$$
\chi_{0} \tilde{Z}_{t}^{1-\sigma_{C}} L_{t}^{\sigma_{L}} \tilde{C}_{t}^{\sigma_{C}}=\tilde{W}_{t}
$$

and the consumption Euler equation

$$
\frac{1}{R_{t}}=\beta E_{t}\left(\frac{\tilde{C}_{t}}{\tilde{C}_{t+1}}\right)^{\sigma_{C}} \frac{\tilde{P}_{t}}{\tilde{P}_{t+1}}\left(E_{t} V_{t+1}^{1-\gamma}\right)^{\frac{\gamma}{1-\gamma}} V_{t+1}^{-\gamma}
$$

If the stochastic discount factor is defined as follow

$$
M_{t+1}=\left[\frac{V_{t+1}}{\left(E_{t} V_{t+1}^{1-\gamma}\right)^{\frac{1}{1-\gamma}}}\right]^{-\gamma}\left(\frac{\tilde{C}_{t}}{\tilde{C}_{t+1}}\right)^{\sigma_{C}}
$$

Then the former equation becomes

$$
\frac{1}{R_{t}}=\beta E_{t} \frac{M_{t+1}}{\Pi_{t+1}}
$$


Firms: There is a continuum of intermediary good producers $(f \in[0,1])$ that combine labour and capital, which is fixed over time, using the following production function

$$
\tilde{Y}_{t}(f)=\tilde{Z}_{t}\left(L_{t}(f)\right)^{1-\phi} K^{\phi}
$$

where $\phi$ is the capital share in the production function. Furthermore, capital is assumed to be firm specific (Woodford (2003), Altig et al. (2011), Rudebusch and Swanson (2012)) and this implies that marginal cost is different across firms

$$
M C_{t}(f)=\frac{\tilde{W}_{t} L_{t}(f)}{(1-\phi) \tilde{Y}_{t}(f)}
$$

Firms sets price in a staggered manner, every period the firm with a probability $1-\xi$ receives a random signal and it is allowed to reset prices optimally $\left(\breve{P}_{t}(f)\right)$

$$
\max _{\breve{P}_{t}(f)} E_{t} \sum_{j=0}^{\infty} M_{t, t+j}(\beta \xi)^{j}\left[\left\{\frac{\breve{P}_{t}(f)}{\tilde{P}_{t+j}}-M C_{t+j}(f)\right\} \tilde{Y}_{t+j}(f)\right]
$$

If the firm misses this signal then it is not permitted to reset its price (Calvo (1983)).

The final output produced by combining the output produced by intermediate firms and the following CES function

$$
\tilde{Y}_{t}=\left[\int_{0}^{1} \tilde{Y}_{t}(f)^{\frac{\varepsilon-1}{\varepsilon}} d f\right]^{\frac{\varepsilon-1}{\varepsilon}}
$$

where $\varepsilon$ denotes the elasticity of substitution between the differentiated goods produced in each country. The final good producer's demand curve for $\tilde{Y}_{t}(f)$ arises from the profit minimisation problem $-\max _{\tilde{Y}_{t}(f)}\left\{\tilde{P}_{t}\left[\int_{0}^{1} \tilde{Y}_{t}(f)^{\frac{\varepsilon-1}{\varepsilon}} d f\right]^{\frac{\varepsilon-1}{\varepsilon}}-\int_{0}^{1} \tilde{P}_{t}(f) \tilde{Y}_{t}(f)\right\}-$ namely

$$
\tilde{Y}_{t}(f)=\left(\frac{\tilde{P}_{t}(f)}{\tilde{P}_{t}}\right)^{-\varepsilon} \tilde{Y}_{t}
$$

The maximisation problem (15) is subject to the constraint (17) and it descirbes firms' optimal pricing decisions:

$$
\begin{aligned}
\tilde{K}_{p, t}(f) & =M C_{t}(f) \tilde{Y}_{t}(f)+\beta \xi E_{t} M_{t+1} \Pi_{t+1}^{\varepsilon} \tilde{K}_{P, t+1}(f) \\
\tilde{F}_{p, t}(f) & =\tilde{Y}_{t}(f)+\beta \xi E_{t} M_{t+1} \Pi_{t+1}^{\varepsilon-1} \tilde{F}_{P, t+1}(f) \\
\bar{\Pi}_{t}(f) & =\frac{\varepsilon}{\varepsilon-1} \frac{K_{P, t}(f)}{F_{P, t}(f)}
\end{aligned}
$$


Government: The government in this economy runs a balance budget

$$
\tilde{P}_{t} \tilde{G}_{t}+D_{t-1}=T_{t}+\frac{D_{t}}{R_{t}}
$$

where $G_{t}$ is government consumption and $g_{t}$ is the of the government share in the economy

$$
\tilde{G}_{t}=g_{t} \tilde{Y}_{t}
$$

that evolves in a stochastic manner

$$
\hat{g}_{t}=g+\rho_{g}\left(\hat{g}_{t-1}-g\right)+\sigma_{g} \omega_{g, t}
$$

Monetary policy is set based on Taylor Type rule

$$
\log \left(R_{t}\right)=r_{t}=\rho_{R} r_{t-1}+\left(1-\rho_{R}\right)\left(\zeta_{\Pi} \log \left(\frac{\Pi_{t}}{\Pi}\right)+\zeta_{Y^{d}}+\log \left(\frac{Y_{t}}{Y_{t-1}}\right)\right)+\sigma_{R} \epsilon_{R, t}
$$

where $\Pi$ is the inflation target, $\rho_{R}$ is the interest rate smoothing parameter, $\zeta_{\Pi}$ and $\zeta_{Y^{d}}$ are the policy reaction coefficients to inflation and demand growth, respectively.

Aggregation: The aggregated labour quantity demanded by firms is:

$$
L_{t}=\int_{0}^{1} L_{t}(f) d f
$$

and it is equal to the quantity supplied by household due the flexibility of wages. Using the latter equation and the intermediate good producer's production function, we obtain

$$
\tilde{Y}_{t}=\frac{\tilde{Z}_{t} L_{t}^{1-\phi} K^{\phi}}{\left[\int_{0}^{1}\left(\frac{\tilde{P}_{t}(h)}{\tilde{P}_{t}}\right)^{-\frac{\varepsilon}{1-\phi}} d h\right]^{1-\phi}}=\frac{\tilde{Z}_{t} L_{t}^{1-\phi} K^{\phi}}{\Delta_{t}}
$$

where $\Delta_{t}$ denotes the price dispersion and it evolves over time as follows:

$$
\Delta_{t}^{\frac{1}{1-\phi}}=(1-\xi) \bar{\Pi}_{t}^{-\frac{\varepsilon}{1-\phi}}+\xi \Pi_{t}^{\frac{\varepsilon}{1-\phi}} \Delta_{t-1}^{\frac{1}{1-\phi}}
$$

Finally, using the expression about the aggregate profits:

$$
\begin{aligned}
& \Xi_{t}=\tilde{P}_{t} \tilde{Y}_{t}-\int_{0}^{1} \tilde{P}_{t}(h) \tilde{Y}_{t}(h)+\int_{0}^{1} \tilde{P}_{t}(h) \tilde{Y}_{t}(h)-\tilde{P}_{t} \tilde{W}_{t} \int_{0}^{1} L_{t}(h) \\
& \Xi_{t}=\tilde{P}_{t} \tilde{Y}_{t}-\tilde{P}_{t} \tilde{W}_{t} L_{t}
\end{aligned}
$$


and households budget constraint we derive the market clearing condition:

$$
\frac{\tilde{Z}_{t} L_{t}^{1-\phi} K^{\phi}}{\Delta_{t}}=\tilde{C}_{t}+\tilde{G}_{t}
$$

The de-trended and steady-state calculations are discussed on the Appendix C.

\subsection{Calibration}

The model is calibrated using simulated methods of moments techniques (Canova (2005), RugeMurcia (2012)) 4 $^{4}$ However, the value of a small number of parameters is decided prior to the minimisation. To be precise, the share of capital in the production $(\phi)$ has been calibrated to 0.36, a number typically used in the literature (Christiano et al. (2005), Trabandt and Uhlig (2011) and Jermann and Quadrini (2012)). Similar to Smets and Wouters (2007) and Christiano et al. (2005) the steady-state value of domestic producers' markup is $20 \%(\epsilon=6)$. The calibration of the Taylor rule is quite standard, the inflation and output reaction parameters are set to 1.50 and 0.125 , respectively. The steady state value of output and hours have been set equal to 1 and $1 / 3$, respectively. Finally, the standard deviations of all shocks have been set equal to 0.005 .

Table 1: Calibrated Parameters

\begin{tabular}{c|l|c}
\hline \hline & & \\
Parameters & Description & Values \\
\hline \hline$\phi$ & Capital Production Share & 0.360 \\
$\epsilon$ & Intermediate Goods Elasticity of Substitution & 6.000 \\
$\zeta_{\Pi}$ & Policy Response to Inflation & 1.500 \\
$\zeta_{Y^{d}}$ & Policy Response to Demand Growth & 0.125 \\
$\sigma_{R}$ & Standard Deviation of Policy Shock & 0.005 \\
$\sigma_{z}$ & Standard Deviation of Productivity Shock & 0.005 \\
$\sigma_{g}$ & Standard Deviation of Government Share Shock & 0.005 \\
\hline \hline
\end{tabular}

The parameters $\beta, \Pi, Z, \sigma_{C}, \sigma_{L}, \gamma, \xi, \rho_{R}, \rho_{z}$ and $\rho_{g}$ are selected to match, the average values of inflation, policy rate, term-premium, the standard deviations of output, inflation, term-spread, term-premium, the first order autocorrelations of output, inflation, the correlation between the term-spread and output and, finally, the correlation between the term-spread and inflation. The model is solved using third-order perturbation methods. To avoid explosive solutions we follow Kim et al. (2008) and Andreasen et al. (2013) and we 'prune' all those terms that have an order that is higher than the approximation order $5^{5}$

\footnotetext{
${ }^{4}$ Although Andreasen et al. (2013) derive closed form expressions for the moments of a third approximated DSGE model, these formulations rely on Kronecker products and due to Matlab computation memory requirements can only be applied to a small scale DSGE models. This implies that the DSGE implied moments can be produced only via simulation.

${ }^{5}$ All the calculations have implemented using Dynare 4.4.3. The model and replication files can be downloaded from authors' webpages.
} 
Table 2: Parameters Selected Using SMM

\begin{tabular}{c|l|c}
\hline \hline & & \\
Parameters & Description & Values \\
\hline \hline$\beta$ & Time Discount Factor & 0.9999 \\
$\Pi$ & Inflation Target & 1.0082 \\
$Z$ & Steady State Value of Productivity Growth & 1.0041 \\
$\sigma_{C}$ & Inverse of Intertemporal Elasticity of Substitution & 1.7960 \\
$\sigma_{L}$ & Inverse of Frisch Elasticity & 4.0000 \\
$\gamma$ & Epstein-Zin Preference Risk & -4.0000 \\
$\xi$ & Calvo Probability & 0.8818 \\
$\rho_{R}$ & Interest Rate Smoothing & 0.5985 \\
$\rho_{z}$ & Persistence of Productivity Growth Process & 0.6754 \\
$\rho_{g}$ & Persistence of Government Share Process & 0.9316 \\
\hline \hline
\end{tabular}

The values of $\beta, \Pi$ and $Z$ imply that the non-stochastic steady-state of annual inflation is $3.26 \%$, output growth $1.65 \%$ and the policy rate $6.25 \%$. Firms reset prices every two years, finally we use the expressions developed by Swanson (2012) to calculate that the coefficient of relative risk aversion is 3.03 .

Table 3: Moments Comparison

\begin{tabular}{l|l|c|c}
\hline \hline \multirow{3}{*}{ Moments } & Variables & Data & Model \\
\hline \hline \multirow{3}{*}{ Mean } & Policy Rate & 1.39 & 1.38 \\
& Inflation & 0.79 & 0.68 \\
& Term Premia & 0.52 & 0.65 \\
\hline \multirow{5}{*}{ Standard Deviation } & Output & 1.45 & 1.41 \\
& Inflation & 0.54 & 0.58 \\
& Policy Rate & 0.99 & 0.90 \\
& Slope & 0.40 & 0.69 \\
& Term Premia & 0.27 & 0.21 \\
\hline \multirow{5}{*}{ st Order Autocorrelation } & Output & 0.88 & 0.92 \\
& Inflation & 0.90 & 0.79 \\
& Policy Rate & 0.97 & 0.81 \\
& Slope & 0.88 & 0.72 \\
& Term Premia & 0.95 & 0.97 \\
\hline Correlation & Output, Slope & -0.48 & -0.20 \\
& Output, Inflation & -0.52 & -0.51 \\
\hline \hline
\end{tabular}

Notes: The DSGE implied moments have been produced using 2000 simulated data points.

Table 3 compares the moments implied by the model (not only those used in the estimation) against their data counterparts. Even though the model is extremely stylised and there are only a small number of random disturbances, it is capable of replicating data moments fairly well. 


\subsection{Conditional Heteroskedasticity}

The novel part of our analysis is that we focus on the volatility implications of the monetary policy shock. With the term volatility we refer to the conditional heteroscedastic response of a variable say $x_{t}$ defined as in Swanson (2015)

$$
\sigma_{x, t}=100 \frac{\left[E_{t}\left(x_{t+1}-E_{t} x_{t+1}\right)^{2}\right]^{\frac{1}{2}}}{\sigma_{x}}
$$

where $\sigma_{x}$ is the unconditional (steady-state) standard deviation of the variable $x_{t}$. As it is explained in Rudebusch and Swanson (2012) and Swanson (2015), the higher moments of economy's endogenous state vector are time-varying $\left(\sigma_{x, t}\right)$ due to the Epstein-Zin preferences and the additive separability of consumption in the period utility function. According to these authors the additive separability property of consumption makes the model non-homogeneous and this is what induces a small degree of conditional heteroscedasticity, which is further enhanced by the risk aversion parameter $(\gamma)$.

The economic intuition behind these two technical conditions is as follows. The specific life time utility functional form breaks the link between the intertemporal elasticity of substitution parameter and the coefficient of relative risk aversion (induced by 'standard' preferences) and agents in these economies prefer an early resolution of uncertainty over future consumption. ${ }^{6}$ As explained in Colacito and Croce (2013) this creates an endogenous trade-off between expected utility and variance utility, meaning that agents are happy to give away some expected future consumption in order to mitigate the risks of future expected consumption (precautionary motives). This feature combined with the additive separability of consumption makes agents' responses to depend on the current level of consumption/output (state of the economy). This implies that when the current level of the marginal utility of consumption is high (or level of consumption/output is low) then consumption uncertainty is higher (relative to the case where the intial level of consumption/output is high) and this reflects agents' elevated concerns about future shocks. This is because an adverse shock that lowers output further is going to induce a proportionally larger reduction in consumption relative to the case where the initial level of counsumpton/output was high (Rudebusch and Swanson (2012)).

\subsection{Impulse Response Analysis}

Figure 3 illustrates what happens to the economy after a monetary policy shock. We plot the generalised impulse responses (Koop et al. (1996)) of the non-linear model (red solid line) against the responses of the linearly approximated model (blue dashed line). Since both sets of responses are fairly similar, we can conclude safely that the results are driven mostly by the first order dynamics and the additional polynomial solution terms allows us to view the

\footnotetext{
${ }^{6}$ This is true when the degree of risk aversion exceeds the intertemporal elasticity of substitution parameter, which is the case in this paper.
} 


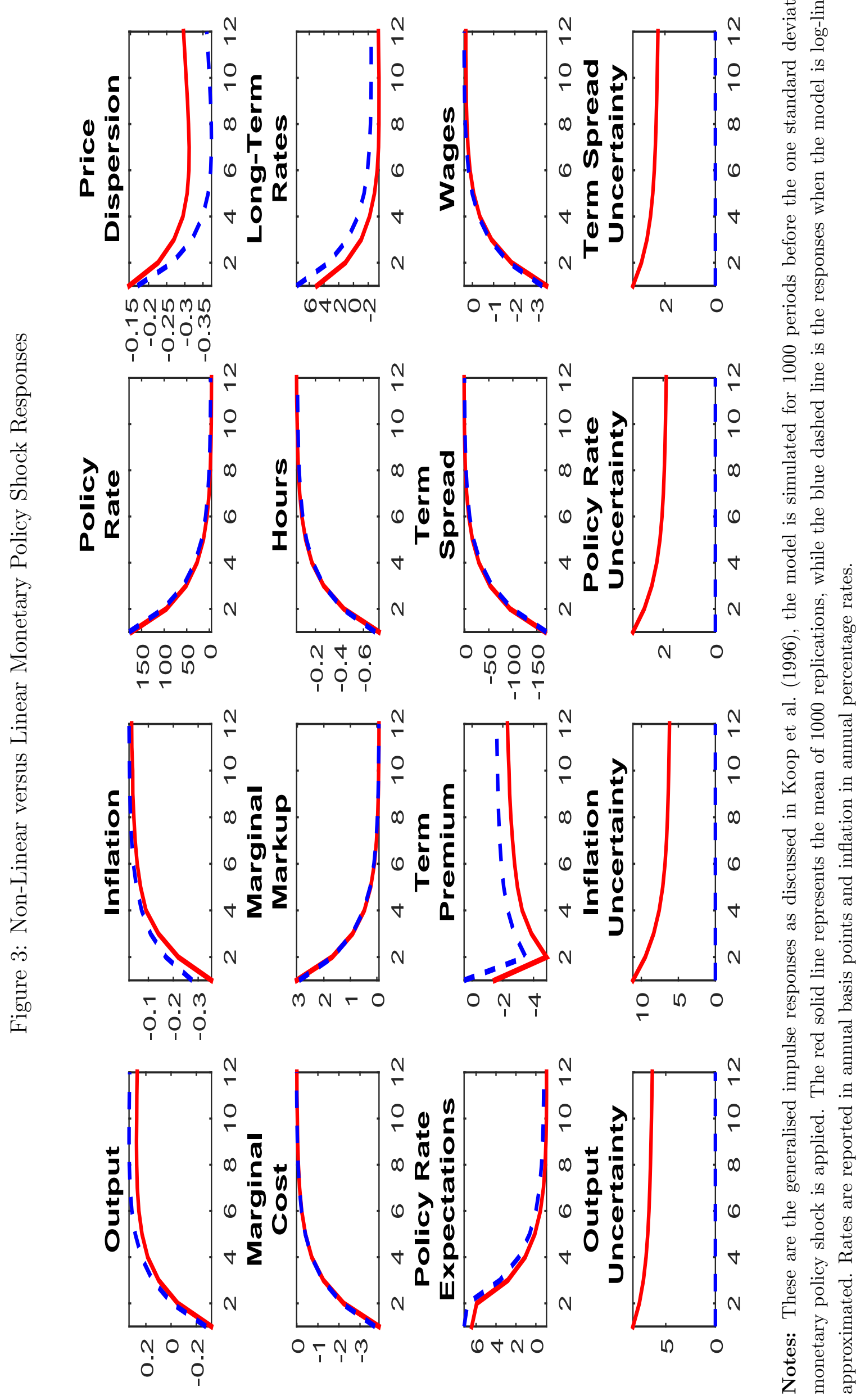




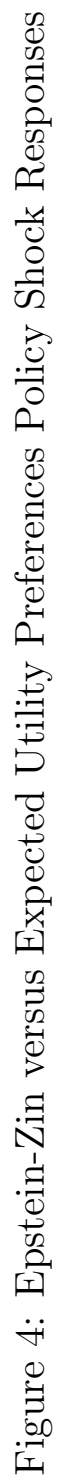

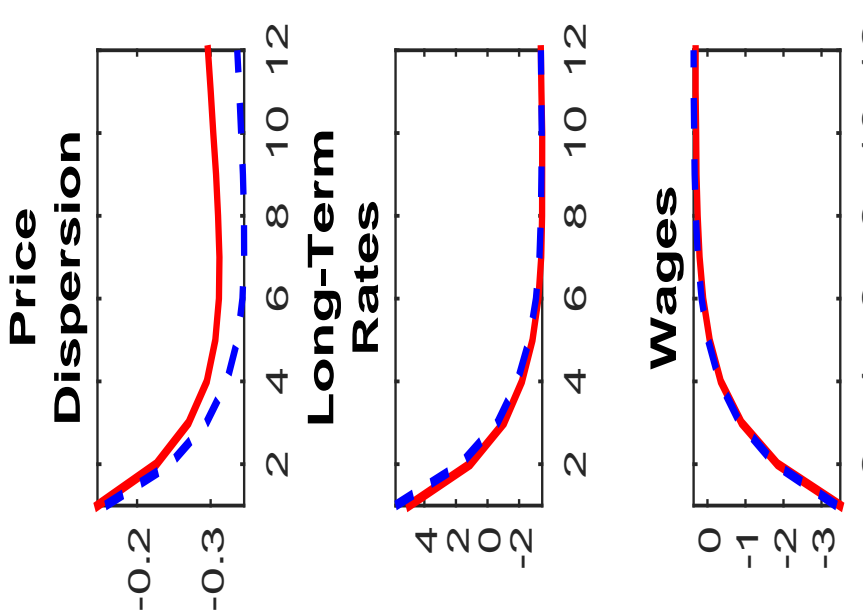

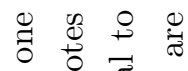

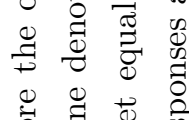

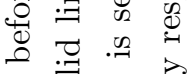

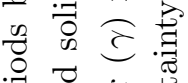

出

脑

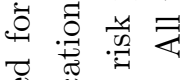

壳

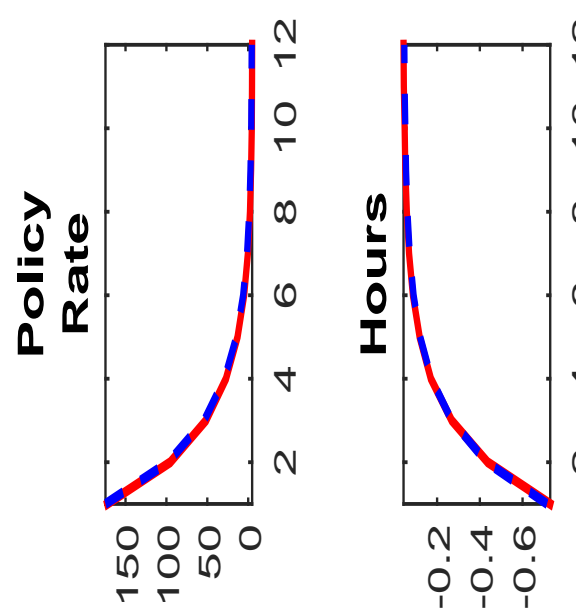

0 in

8 至

: 0000

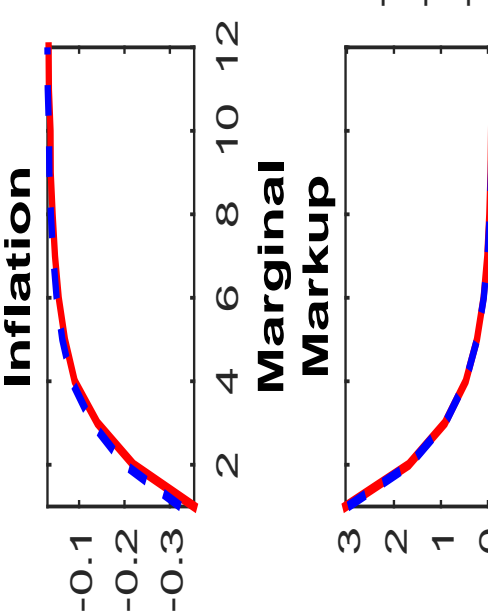

$\stackrel{0}{2}$

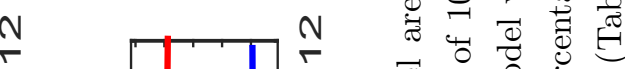

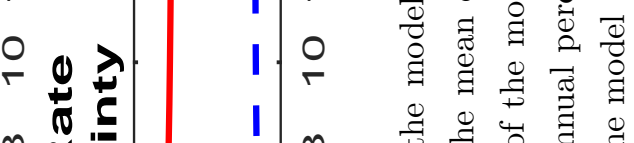

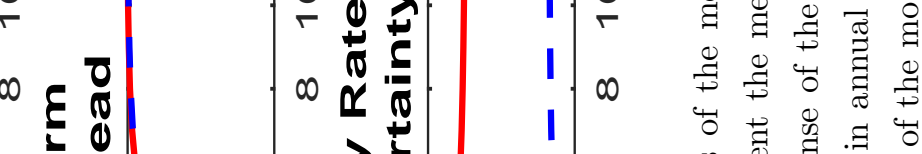

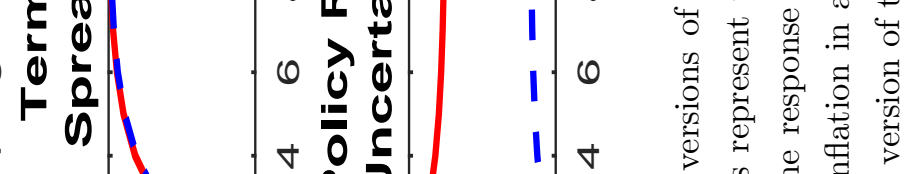
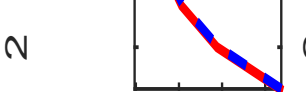

0000

MNTOT

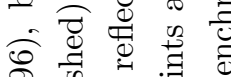

娄 0

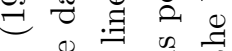
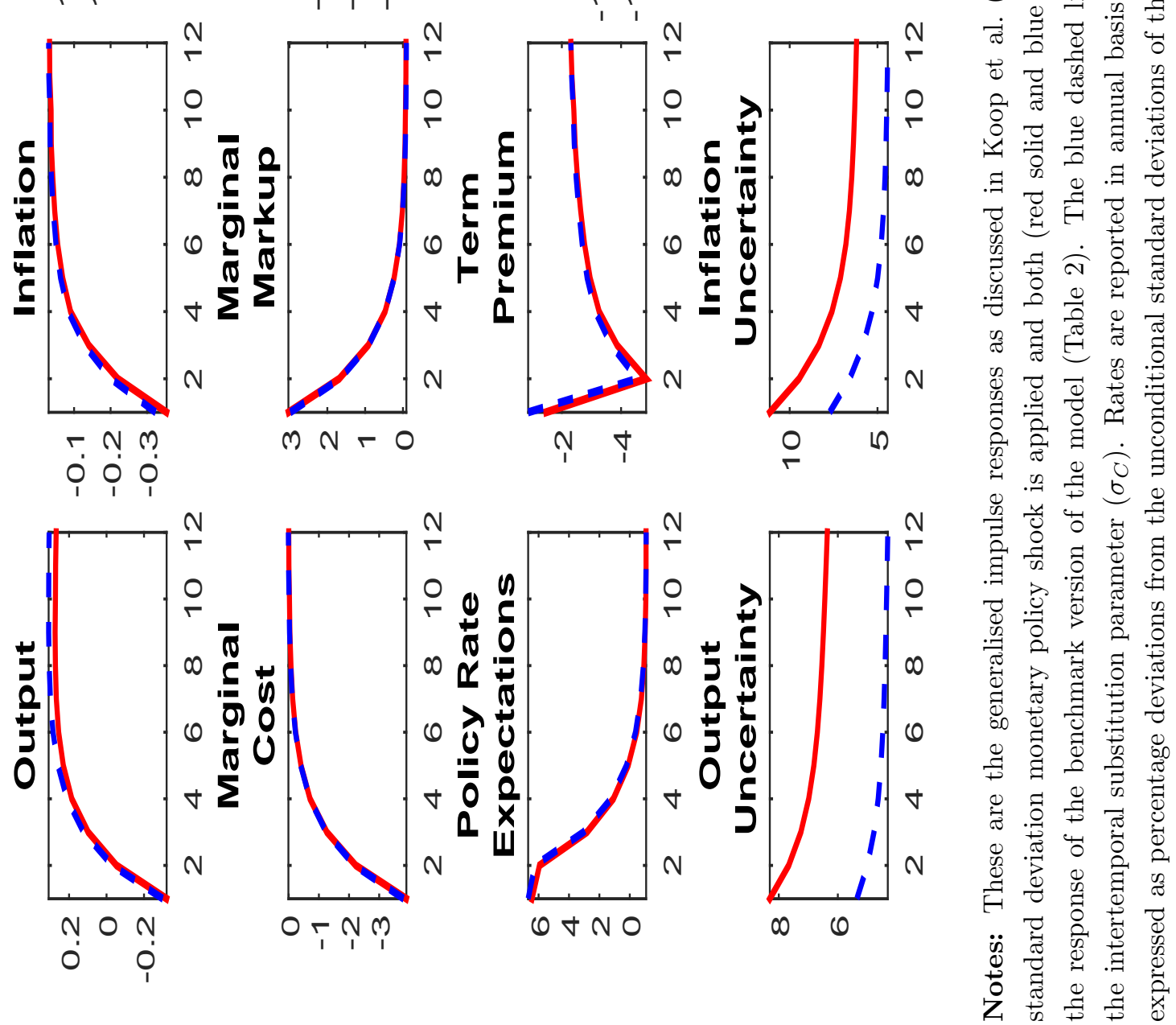


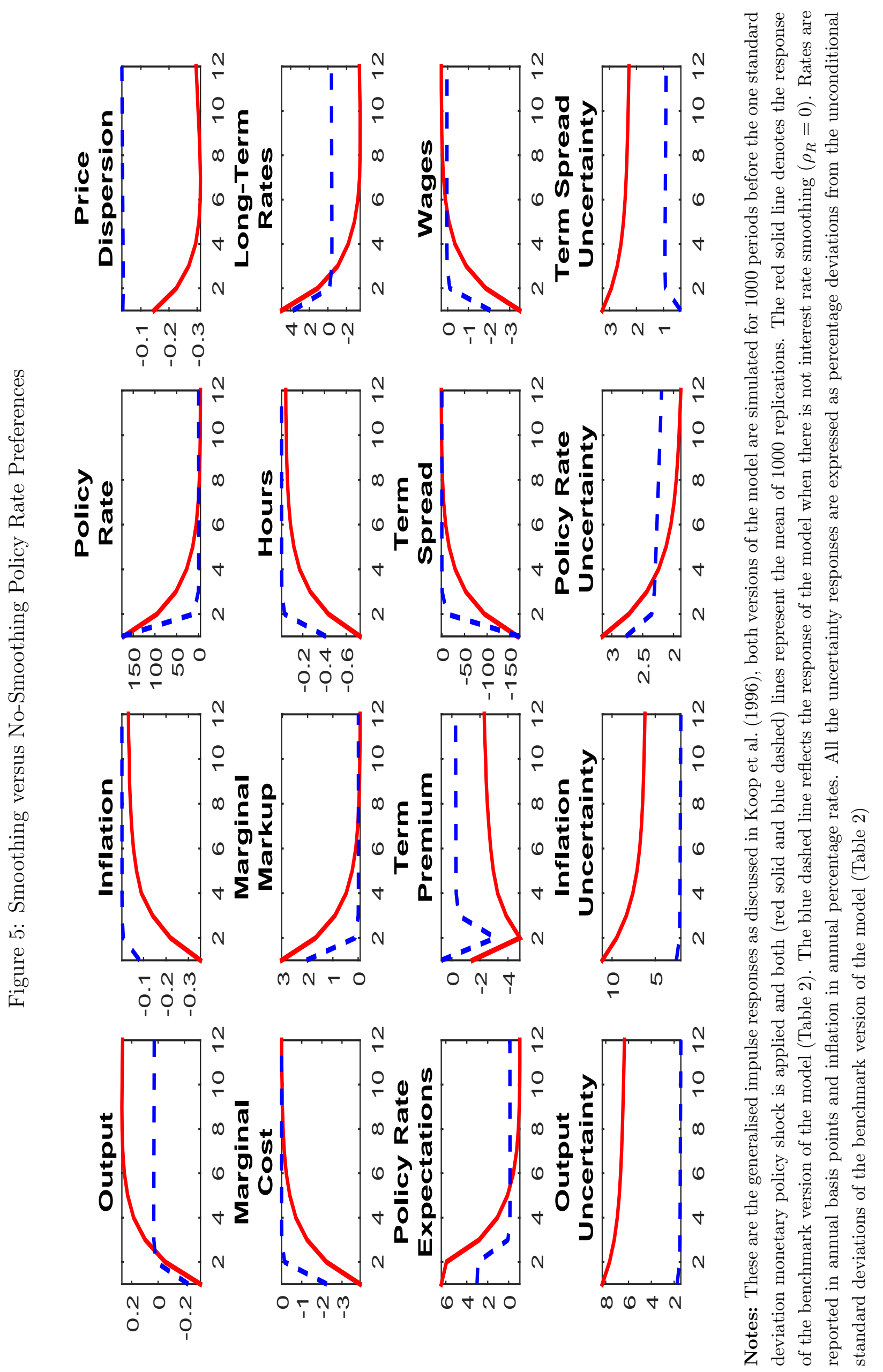



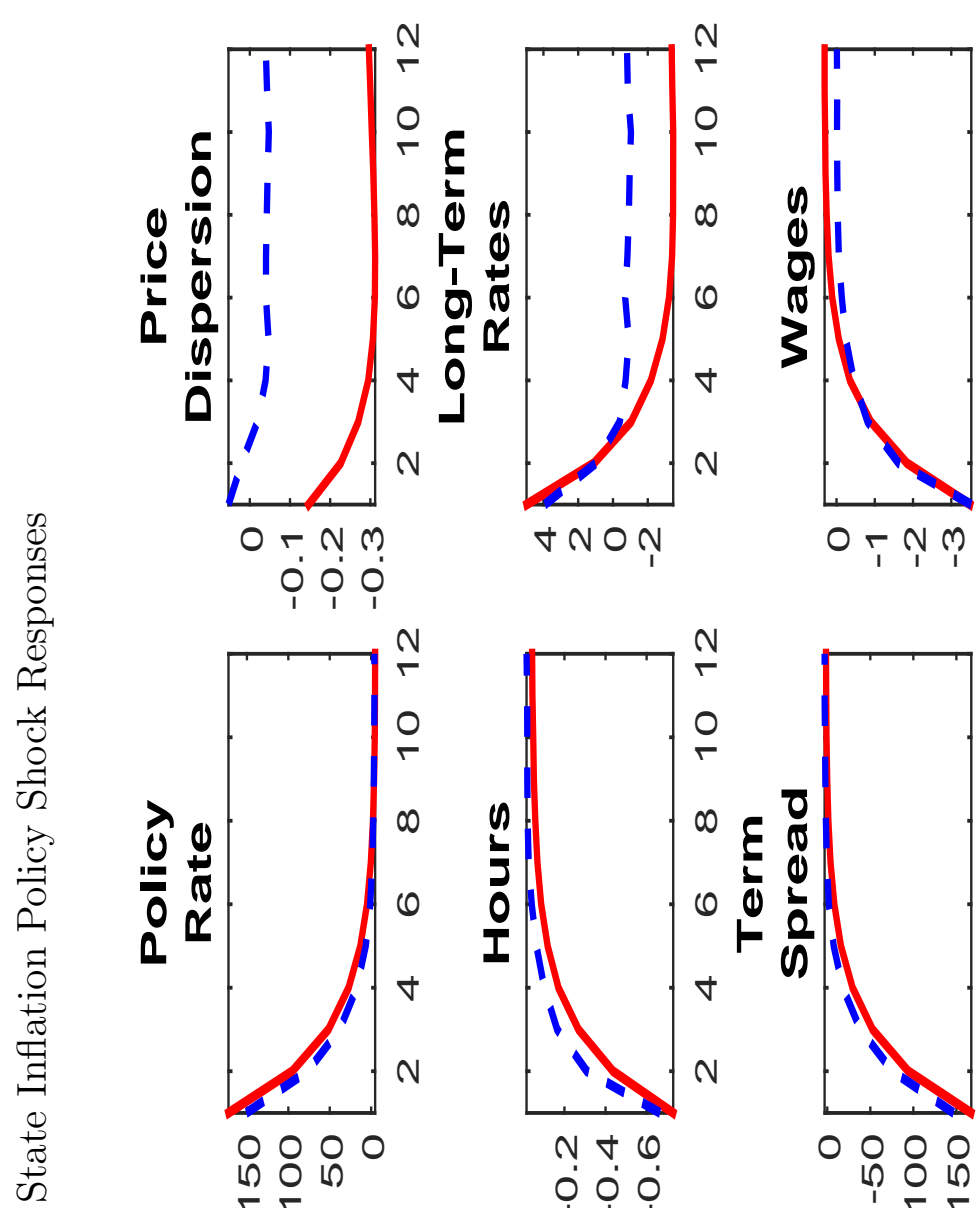

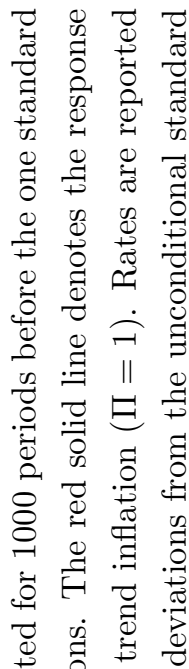
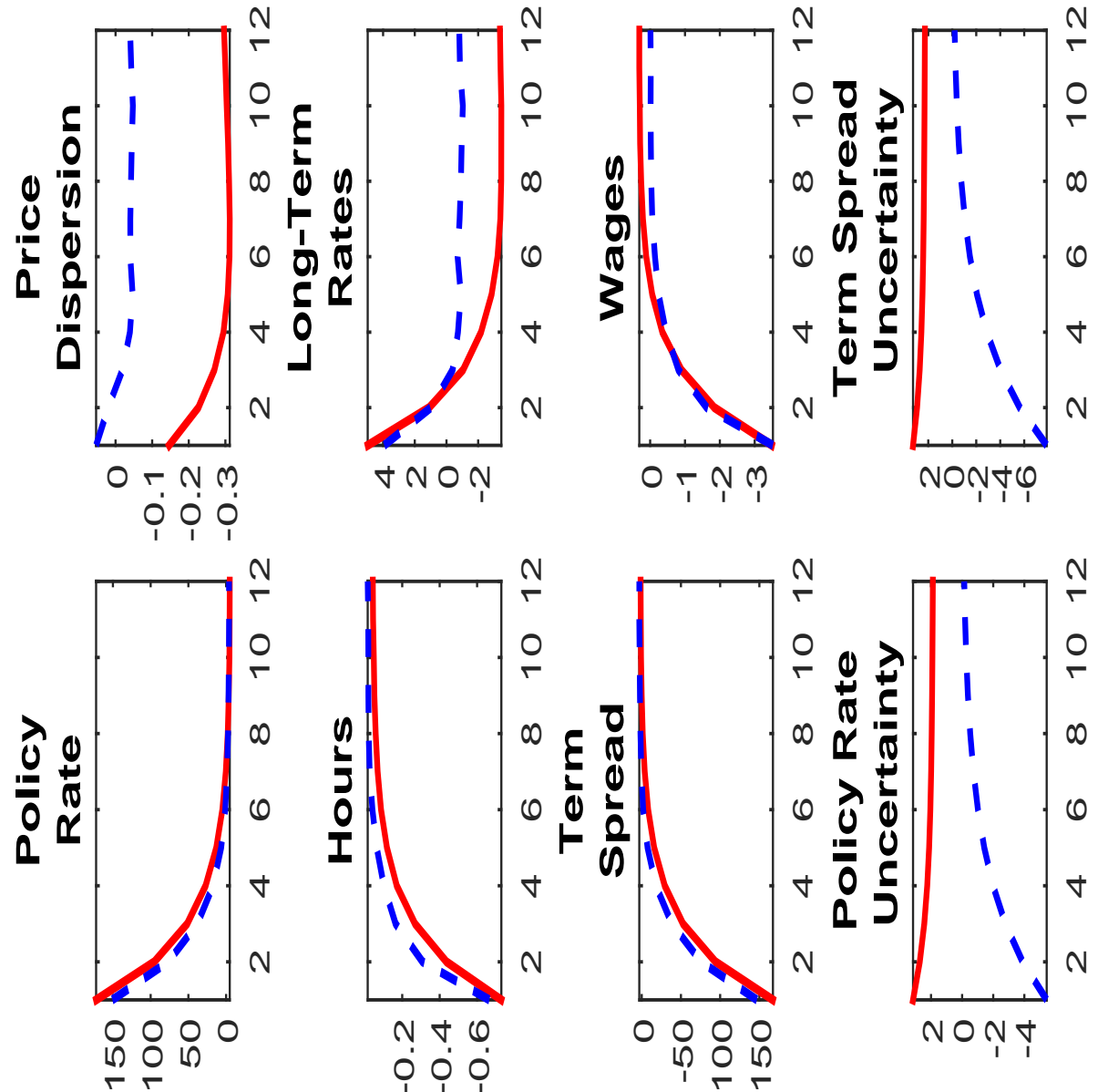

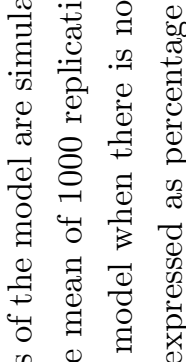

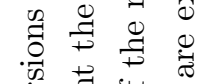

可

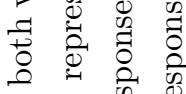

胥

ํํㄴ

2
3
0
0
0
0
0
0
0
0
0
0
0
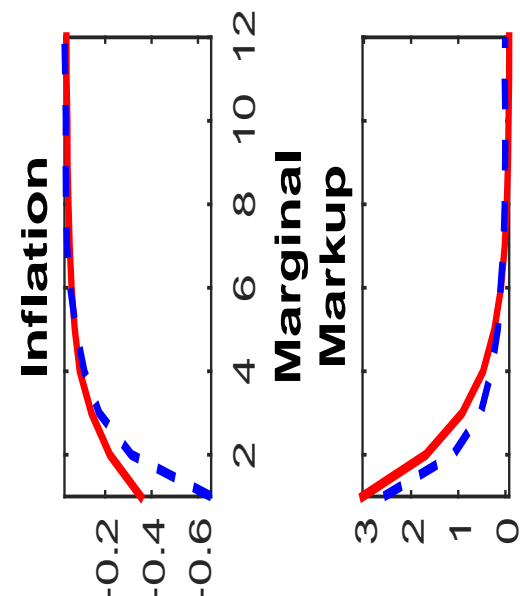

(0) 0

兽焉焉

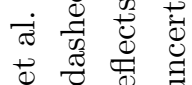

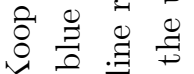

结孚卷

荡

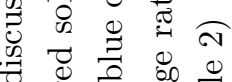

足

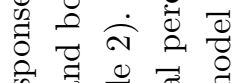

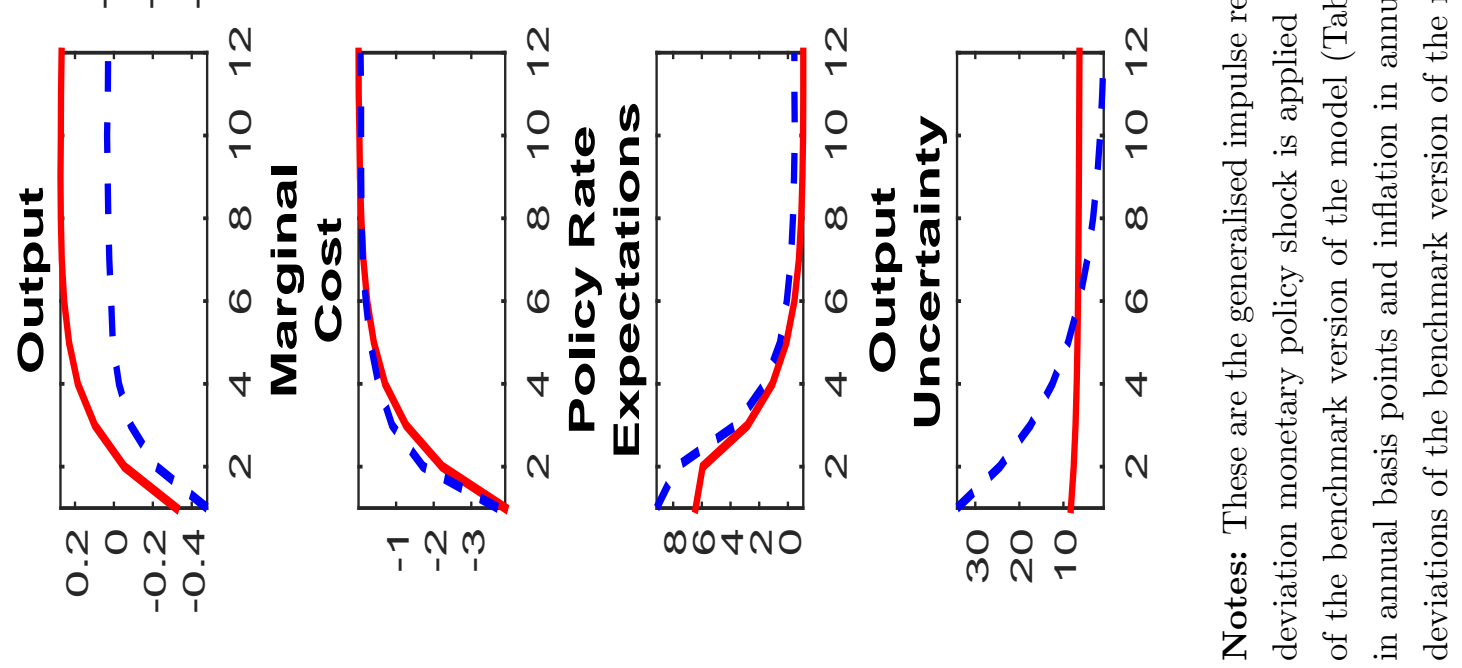


uncertainty implications of the monetary policy shock. This is an interesting outcome as it suggests that most our analysis applies to a large class of models.

This is also supported by Figure 4, where in this exercise the blue dashed illustrates the model variable nonlinear responses to a monetary policy shocks when the Epstein-Zin risk parameter $(\gamma)$ is set equal to the inverse of intertemporal elasticity of substitution parameter $\left(\sigma_{C}\right)$. This cancels the nonlinearities induced by the recursive preferences (trade-off between expected utility and variance utility) and reduces the coefficient of relative risk aversion to zero. Relative to the benchmark calibration (red solid line) the uncertainty effects are mitigated, which is entirely consistent with the analysis in Rudebusch and Swanson (2012), Swanson (2015) and the discussion in Section 3.3. To be precise, Rudebusch and Swanson (2012) and, more explicitly, Swanson (2015) argue that it is the functional form of the period utility function (additively separable consumption) that generates a small degree of conditional heteroscedasticity, which is boosted further by the risk aversion parameter $(\gamma)$. When $\gamma$ is set equal to $\sigma_{C}$ this additional enhancement does not take place and the the volatility effects of a monetary policy shock are expected to be smaller.

The difference between the responses with Epstein-Zin and expected preferences (red solid and blue dashed line respectively, Figure 4 is not significant in economic terms and somebody could object the usefulness of the recursive preference specification adopted here. Although, this statement is correct, it is conditional on the (very) small value of the coefficient of relative risk aversion required for the model to be able to match the moments in the data (Table 3 ). Our estimate falls definitely to the lower end of the values used/estimated in the literature (Piazzesi and Schneider (2007) van Binsbergen et al. (2012), Andreasen (2012), Rudebusch and Swanson (2012) and Swanson (2015)), suggesting that the volatility increase after a contractionary monetary policy shock could be even more dramatic if a number closer to the literature has had been selected.

It is perhaps not difficult to understand why output volatility increases after an adverse monetary policy shock. As the policy rate rises agents find it optimal to substitute current with expected consumption. Lower current consumption induces households to supply more labour, pushing down wages, marginal cost and, consequently, inflation. Although both demand and inflation contract, authorities loosen policy only by a little due to their smoothing preferences. Agents are risk averse and policymakers' actions to restore equilibrium only gradually triggers their concerns about their future consumption levels as their labour income decreases dramatically. Figure 5 illustrates what happens when authorities' objective function is not subject to interest rate smoothing (blue dashed line). Relative to the benchmark calibration of the model (red solid line), it can be seen that authorities are able to restore the steady-state on the second period and this reduces the volatility in the economy dramatically.

It is perhaps less obvious why inflation volatility rises after an unexpected policy rate increase. If inflation is viewed as a social cost and a positive monetary policy shock suppresses the rate at which prices rise, then agents should be less concerned about inflation in those episodes. 
Although this statement is likely to be correct in most cases, it ignores the pricing behavior of the firms and, particularly, in those circumstances when steady-state inflation is non-zero. As demand contracts, firms who receive the random signal are able to reoptimise profits by setting a lower price. However, while they do that they are aware of the following: (i) that inflation has a trend and (ii) the possibility that they may remain with this price for some time. The combination of these two features will cause severe loses to firms and these concerns are reflected by the elevated inflation volatility generated after a contractionary monetary policy shock.

Figure 6 investigates further the link between the non-zero steady-state inflation and the macroeconomic volatility. The blue dashed line on this experiment illustrates what happens to agents' responses after an unexpected tightening on the monetary policy when the trend inflation is switched off; they are plotted against the benchmark impulse responses (red solid line). The results are intriguing, when the steady-state inflation is set to zero then real (output) volatility increases dramatically (by more than $30 \%$ above its steady-state standard deviation), while the standard deviation of inflation decreases (by more than $10 \%$ below its its steady-state standard deviation). As explained by Ascari and Sbordone (2014) the slope of the Phillips curve is a function of the steady-state inflation and when this is not zero then the Phillips curve becomes flatter. This reflects that agents become more forward looking since expected inflation is going to erode their average markup (King and Wolman (1999)). However, as the Phillips curve becomes flatter the ability of the monetary authorities to bring inflation back to its target diminishes and long term rates need to stay low for longer (relative to the zero steady-state inflation case) for this to occur. This stimulates demand from the fifth quarter onwards mitigating the output risks caused by the adverse monetary policy shock. In other words, a small positive steady-state inflation seems to have beneficial effects on the output volatility when authorities set policies based on a Taylor type objective function. King and Wolman (1996) and King and Wolman (1999) (amongst others) have already shown that a small positive inflation can increase welfare by acting as tax on firms average markup. Here we illustrate that a small positive steady-state inflation can have a beneficial impact vis-à-vis output volatility.

Due to the linearity of the Taylor rule the volatility of the policy rate simply reflects the inflation and the output growth volatility. However, the volatility of the long-term interest rate seems to be associated with the inflation and not the output volatility (see Figures 3- 6), which is again consistent with the work of Piazzesi and Schneider (2007), Rudebusch and Swanson (2012) and Swanson (2015) (amongst others). In this model there is no default or/and liquidity type frictions and it is only the inflation that can erode the capital gains from investing on long-term debt and this is why volatility about the long-term interest rates reflects (mainly) concerns about the inflation. 


\section{Conclusion}

This study investigates the response of macroeconomic volatility to an unexpected increase in the policy rate. For this purpose we use a simple New Keynesian model, with firm specific capital, non-zero steady-state inflation, long-run risks and Epstein-Zin preferences. The model is calibrated to match a set of macroeconomic and financial moments using US data. Simulations from the theoretical model reveal that a monetary policy shock that increases the policy rate by 150 basis points causes output and inflation volatility to rise by around $10 \%$ above its unconditional value. This result matches empirical evidence based on a SVAR with stochastic volatility. The slope of the Phillips curve, which also depends on the size of the steady state inflation, induces a trade off between real and nominal uncertainty. Non zero steady-state inflation makes the agents in the model to be more forward looking and decreases the effectiveness of policy actions to restore inflation back to its target. This induces authorities to keep rates low for longer, which pushes output above its steady-state after the first year. This elevated demand required to bring inflation back to its target, mitigates the real uncertainty effects of a monetary policy shock. When there is no trend inflation the Phillips curve is significantly steeper and a monetary policy shock increases real uncertainty by more than $30 \%$, while nominal uncertainty decreases by more than $10 \%$.

In future work it would be interesting to explore if this relationship between the policy shock and macroeconomic volatility extends to industrialised countries other than the United States and if there is any significant cross-country variation. It may also be instructive to examine if the impact of monetary policy shock on second moments has changed over time. 


\section{References}

Altig, D., L. Christiano, M. Eichenbaum, And J. Linde (2011): "Firm-Specific Capital, Nominal Rigidities and the Business Cycle," Review of Economic Dynamics, 14, 225-247.

Andreasen, M. M. (2012): "An estimated DSGE model: Explaining variation in nominal term premia, real term premia, and inflation risk premia," European Economic Review, 56, $1656-1674$.

Andreasen, M. M., J. Fernandez-Villaverde, and J. Rubio-Ramirez (2013): “The Pruned State-Space System for Non-Linear DSGE Models: Theory and Empirical Applications," Working Paper 18983, National Bureau of Economic Research.

Ascari, G., A. Florio, And A. Gobbi (2015): "Transparency, Expectations Anchoring and the Inflation Target," DEM Working Papers Series 022, University of Pavia, Department of Economics and Management.

Ascari, G. And L. Rossi (2012): "Trend Inflation and Firms PriceSetting: Rotemberg Versus Calvo," Economic Journal, 122, 1115-1141.

Ascari, G. And A. M. Sbordone (2014): "The Macroeconomics of Trend Inflation," Journal of Economic Literature, 52, 679-739.

Banbura, M., D. Giannone, And L. Reichlin (2007): "Bayesian VARs with Large Panels," CEPR Discussion Papers 6326, C.E.P.R. Discussion Papers.

Bikbov, R. And M. Chernov (2013): "Monetary policy regimes and the term structure of interest rates," Journal of Econometrics, 174, 27-43.

Blanchard, O., G. Dell'Ariccia, and P. Mauro (2010): "Rethinking Macroeconomic Policy," Journal of Money, Credit and Banking, 42, 199-215.

Bloom, N. (2009): "The Impact of Uncertainty Shocks," Econometrica, 77, 623-85.

Born, B. AND J. Pfeifer (2014): "Policy risk and the business cycle," Journal of Monetary Economics, 68, 68-85.

Calvo, G. A. (1983): "Staggered prices in a utility-maximizing framework," Journal of Monetary Economics, 12, 383-398.

Campbell, J. Y., C. Pflueger, And L. M. Viceira (2014): "Monetary Policy Drivers of Bond and Equity Risks," NBER Working Papers 20070, National Bureau of Economic Research, Inc.

Canova, F. (2005): Methods for applied macroeconomic research, Princeton: Princeton University Press. 
Carlin, B. P., N. G. Polson, And D. S. Stoffer (1992): "A Monte Carlo Approach to Nonnormal and Nonlinear State-Space Modeling," Journal of the American Statistical Association, 87, 493-500.

Carter, C. And P. Kohn (2004): "On Gibbs sampling for state space models," Biometrika, $81,541-53$.

Castelnuovo, E. And P. Surico (2010): "Monetary Policy, Inflation Expectations and The Price Puzzle*," The Economic Journal, 120, 1262-1283.

Chan, J. C. (0): "The Stochastic Volatility in Mean Model with Time-Varying Parameters: An Application to Inflation Modeling," Journal of Business \&6 Economic Statistics, 0, 0-0.

Christiano, L., M. Eichenbaum, And C. Evans (2005): "Nominal Rigidities and the Dynamic Effects of a shock to Monetary Policy," Journal of Political Economy, 113, 1-45.

Clark, T. E. (2011): "Real-Time Density Forecasts From Bayesian Vector Autoregressions With Stochastic Volatility," Journal of Business 65 Economic Statistics, 29, 327-341.

Cogley, T. And T. J. Sargent (2005a): "Drift and Volatilities: Monetary Policies and Outcomes in the Post WWII U.S," Review of Economic Dynamics, 8, 262-302.

- (2005b): "Drifts and Volatilities: monetary policies and outcomes in the Post WWII U.S." Review of Economic Dynamics, 8, 262-302.

Cogley, T. And A. M. Sbordone (2008): "Trend Inflation, Indexation, and Inflation Persistence in the New Keynesian Phillips Curve," American Economic Review, 98, 2101-26.

Coibion, O., Y. Gorodnichenko, and J. Wieland (2012): "The Optimal Inflation Rate in New Keynesian Models: Should Central Banks Raise Their Inflation Targets in Light of the Zero Lower Bound?" Review of Economic Studies, 79, 1371-1406.

Colacito, R. And M. M. Croce (2013): "International Asset Pricing with Recursive Preferences," Journal of Finance, 68, 2651-2686.

Epstein, L. G. And S. E. ZIN (1989): "Substitution, Risk Aversion, and the Temporal Behavior of Consumption and Asset Returns: A Theoretical Framework," Econometrica, 57, 937-69.

Fernandez-Villaverde, J., P. Guerron-Quintana, J. F. Rubio-Ramirez, and M. URIBE (2011): "Risk Matters: The Real Effects of Volatility Shocks," American Economic Review, 101, 2530-61.

Fernandez-Villaverde, J., P. A. Guerron-Quintana, K. Kuester, and J. RubioRAmirez (forthcoming): "Fiscal Volatility Shocks and Economic Activity," American Economic Review. 
Jacquier, E., N. Polson, And P. Rossi (1994): "Bayesian analysis of stochastic volatility models," Journal of Business and Economic Statistics, 12, 371-418.

Jermann, U. And V. QuAdrini (2012): "Macroeconomic Effects of Financial Shocks," American Economic Review, 102, 238-71.

Kim, J., S. Kim, E. Schaumburg, and C. Sims (2008): "Calculating and using secondorder accurate solutions of discrete time dynamic equilibrium models," Journal of Economic Dynamics and Control, 32, 3397 - 414.

King, R. And A. L. Wolman (1999): "What Should the Monetary Authority Do When Prices Are Sticky?" in Monetary Policy Rules, National Bureau of Economic Research, Inc, NBER Chapters, 349-404.

King, R. G. And A. L. Wolman (1996): "Inflation Targeting in a St. Louis Model of the 21st Century," NBER Working Papers 5507, National Bureau of Economic Research, Inc.

Koop, G., H. Pesaran, And S. Potter (1996): "Impulse response analysis in nonlinear multivariate models," Journal of Econometrics, 74, 119-147.

Mumtaz, H. And P. Surico (2013): "Policy Uncertainty and Aggregate Fluctuations," Working Papers 708, Queen Mary University of London, School of Economics and Finance.

Mumtaz, H. AND K. TheOdoridis (2015): "THE INTERNATIONAL TRANSMISSION OF VOLATILITY SHOCKS: AN EMPIRICAL ANALYSIS," Journal of the European Economic Association, 13, 512-533.

Mumtaz, H. And F. Zanetti (2013): "The Impact of the Volatility of Monetary Policy Shocks," Journal of Money, Credit and Banking, 45, 535-558.

Piazzesi, M. AND M. Schneider (2007): "Equilibrium Yield Curves," in NBER Macroeconomics Annual 2006, Volume 21, ed. by D. Acemoglu, K. Rogoff, and M. Woodford, National Bureau of Economic Research, Inc, NBER Chapters, 389-472.

Romer, C. D. And D. H. Romer (2004): "A New Measure of Monetary Shocks: Derivation and Implications," American Economic Review, 94, 1055-1084.

Rudebusch, G. D. And E. T. Swanson (2012): "The Bond Premium in a DSGE Model with Long-Run Real and Nominal Risks," American Economic Journal: Macroeconomics, 4, $105-43$.

Ruge-Murcia, F. (2012): "Estimating nonlinear \{DSGE\} models by the simulated method of moments: With an application to business cycles," Journal of Economic Dynamics and Control, 36, $914-938$.

Smets, F. And R. Wouters (2007): "Shocks and Frictions in US Business Cycles: a Bayesian DSGE Approach," American Economic Review, 97, 586-606. 
Song, D. (2014): "Bond Market Exposures to Macroeconomic and Monetary Policy Risks," PIER Working Paper Archive 14-017, Penn Institute for Economic Research, Department of Economics, University of Pennsylvania.

Swanson, E. (2015): "A Macroeconomic Model of Equities and Real, Nominal, and Defaultable Debt," Mimeo, University of California Irvine.

Swanson, E. T. (2012): "Risk Aversion and the Labor Margin in Dynamic Equilibrium Models," American Economic Review, 102, 1663-91.

Trabandt, M. And H. Uhlig (2011): "The Laffer curve revisited," Journal of Monetary Economics, 58, $305-327$.

van Binsbergen, J. H., J. Fernandez-Villaverde, R. S. Koijen, and J. RubioRAMIREZ (2012): "The term structure of interest rates in a DSGE model with recursive preferences," Journal of Monetary Economics, 59, 634-648.

WeIL, P. (1989): "The equity premium puzzle and the risk-free rate puzzle," Journal of Monetary Economics, 24, 401-421.

- (1990): "Nonexpected Utility in Macroeconomics," The Quarterly Journal of Economics, 105, 29-42.

Whittle, P. (1953): “The Analysis of Multiple Stationary Time Series," 15, 125-139.

WILKS, S. S. (1932): "CERTAIN GENERALIZATIONS IN THE ANALYSIS OF VARIANCE," Biometrika, 24, 471-494.

Woodford, M. (2003): Interest and Prices: Foundations of a Theory of Monetary Policy, Princeton University Press. 


\section{A Model Estimation}

Consider the VAR model

$$
\begin{aligned}
& Z_{t}=c+\sum_{j=1}^{P} \beta_{j} Z_{t-j}+\Omega_{t}^{1 / 2} e_{t}, e_{t} \sim N(0,1) \\
& \Omega_{t}=A^{-1} H_{t} A^{-1^{\prime}} \\
& \tilde{h}_{t}=\alpha+\theta \tilde{h}_{t-1}+\sum_{j=1}^{K} d_{j} Z_{t-j}+\eta_{t}, \eta_{t} \sim N(0, Q), E\left(e_{t}, \eta_{t}\right)=0
\end{aligned}
$$

where $\tilde{h}_{t}=\left[h_{1 t}, h_{2 t}, . . h_{N, t}\right], H_{t}=\operatorname{diag}\left(\exp \left(\tilde{h}_{t}\right)\right)$.

\section{A.1 Prior distributions and starting values}

\section{A.1.1 VAR coefficients}

Following Banbura et al. (2007), we employ a Normal prior implemented via dummy observations. The priors are implemented by the dummy observations $y_{D}$ and $x_{D}$ that are defined as:

$$
y_{D}=\left[\begin{array}{c}
\frac{\operatorname{diag}\left(\gamma_{1} s_{1} \ldots \gamma_{n} s_{n}\right)}{\tau} \\
0_{N \times(P-1) \times N} \\
\ldots \ldots \ldots \ldots \\
0_{1 \times N}
\end{array}\right], \quad x_{D}=\left[\begin{array}{cc}
\frac{J_{P} \otimes \operatorname{diag}\left(s_{1} \ldots s_{n}\right)}{\tau} & 0_{N P \times 1} \\
0_{N \times N P} & 0_{N \times 1} \\
\ldots \ldots \ldots \ldots . . . & \\
0_{1 \times N P} & c
\end{array}\right]
$$

where $\gamma_{1}$ to $\gamma_{n}$ denote the prior mean for the parameters on the first lag obtained by estimating individual $\mathrm{AR}(1)$ regressions, $\tau$ measures the tightness of the prior on the VAR coefficients, and $c$ is the tightness of the prior on the constant term. We set $\tau=0.1$. and $c=1 / 1000$. Note that these dummies do not directly implement a prior belief on the VAR error covariance matrix which is time-varying in our setting.

The priors for the coefficients are thus: $N\left(\Gamma_{0}, P_{0}\right)$ where $\Gamma_{0}=\left(x_{D}^{\prime} x_{D}\right)^{-1}\left(x_{D}^{\prime} y_{D}\right)$ and $P_{0}=$ $S \otimes\left(x_{D}^{\prime} x_{D}\right)^{-1}$ where $S$ is a diagonal matrix with an estimate of the variance of $Z_{t}$ (obtained using the training sample described below) on the main diagonal.

\section{A.1.2 Elements of $H_{t}$}

Following Cogley and Sargent 2005b) we use a training sample (of 120 pre-sample observations from 1947M1 to $1957 \mathrm{M} 12$ ) to set the prior for the elements of the transition equation of the 
model. Let $\hat{v}^{\text {ols }}$ denote the OLS estimate of the VAR covariance matrix estimated on the pre-sample data. The prior for $\tilde{h}_{t}$ at $t=0$ is defined as $\ln h_{0} \sim N\left(\ln \mu_{0}, I_{4}\right)$ where $\mu_{0}$ are the diagonal elements of the Cholesky decomposition of $\hat{v}^{\text {ols }}$.

\section{A.1.3 Elements of $A$}

The prior for the off-diagonal elements $A$ is $A_{0} \sim N\left(\hat{a}^{\text {ols }}, V\left(\hat{a}^{\text {ols }}\right)\right)$ where $\hat{a}^{\text {ols }}$ are the offdiagonal elements of $\hat{v}^{\text {ols }}$, with each row scaled by the corresponding element on the diagonal. $V\left(\hat{a}^{\text {ols }}\right)$ is assumed to be diagonal with the elements set equal to 100 . We employ a tighter prior for elements where sign restrictions are imposed.

\section{A.1.4 Parameters of the transition equation}

The prior on the coefficients and error covariance of the transition equation 33 is implemented via dummy variables (see Banbura et al. (2007)), shrinking each equation towards an AR process. This set of artificial data also includes dummy variables to implement the inverse Wishart prior on $Q$ and the coefficients on the predetermined regressors. The prior tightness parameter controlling the strength of the prior on the coefficients on the lagged volatilities is set equal to 0.05 . The parameter that controls the prior tightness on the lagged pre-determined variables is also set to 0.05 .

\section{A.2 Simulating the posterior distributions}

\section{A.2.1 VAR coefficients}

The distribution of the VAR coefficients $\Gamma$ conditional on all other parameters $\Xi$ and the stochastic volatility $\tilde{h}_{t}$ is linear and Gaussian: $\Gamma \backslash Z_{t}, \tilde{h}_{t}, \Xi \sim N\left(\Gamma_{T \backslash T}, P_{T \backslash T}\right)$ where $\Gamma_{T \backslash T}=$ $E\left(\Gamma_{T} \backslash Z_{t}, \tilde{h}_{t}, \Xi\right), P_{T \backslash T}=\operatorname{Cov}\left(\Gamma_{T} \backslash Z_{t}, \tilde{h}_{t}, \Xi\right)$. Following Carter and Kohn (2004) we use the Kalman filter to estimate $\Gamma_{T \backslash T}$ and $P_{T \backslash T}$ where we account for the fact that the covariance matrix of the VAR residuals changes through time. Note that since we condition on $\tilde{h}_{t}$ and $A$, the form of the heteroscedasticity is known. To use the Kalman filter we write the VAR in state space form as

$$
\begin{aligned}
y_{t} & =x_{t} \Gamma_{t}+\left(A^{-1} H_{t} A^{-1^{\prime}}\right)^{1 / 2} e_{t} \\
\Gamma_{t} & =\Gamma_{t-1}
\end{aligned}
$$

The Kalman filter is initialised at $\Gamma_{0}$ and $P_{0}$ and the recursions are given by the following equations for $t=1,2 . . T$ 


$$
\begin{aligned}
\Gamma_{t \backslash t-1} & =\Gamma_{t-1 \backslash t-1} \\
P_{t \backslash t-1} & =P_{t-1 \backslash t-1} \\
\eta_{t \backslash t-1} & =y_{t}-x_{t} \Gamma_{t \backslash t-1} \\
f_{t \backslash t-1} & =x_{t} P_{t \backslash t-1} x_{t}^{\prime}+\left(A^{-1} H_{t} A^{-1^{\prime}}\right) \\
K_{t} & =P_{t \backslash t-1} x_{t}^{\prime} f_{t \backslash t-1}^{-1} \\
\Gamma_{t \backslash t} & =\Gamma_{t \backslash t-1}+K_{t} \eta_{t \backslash t-1} \\
P_{t \backslash t} & =P_{t \backslash t-1}-K_{t} x_{t} P_{t \backslash t-1}
\end{aligned}
$$

The final iteration of the Kalman filter at time $T$ delivers $\Gamma_{T \backslash T}$ and $P_{T \backslash T}$. This application of the Carter and Kohn (2004) algorithm to this heteroscedastic VAR model is equivalent to a GLS transformation of the model.

\section{A.2.2 Element of $A_{t}$}

Given a draw for $\Gamma$ and $\tilde{h}_{t}$ the VAR model can be written as $A^{\prime}\left(\tilde{Z}_{t}\right)=e_{t}$ where $\tilde{Z}_{t}=$ $Z_{t}-c+\sum_{j=1}^{P} \beta_{j} Z_{i t-j}=v_{t}$ and $V A R\left(e_{t}\right)=H_{t}$. This is a system of linear equations with a known form of heteroscedasticity. The conditional distributions for a linear regression apply to each equation of this system after a simple GLS transformation to make the errors homoscedastic. The $i t h$ equation of this system is given as $v_{i t}=-\alpha v_{-i t}+e_{i t}$ where the subscript $i$ denotes the $i$ th column while $-i$ denotes columns 1 to $i-1$. Note that the variance of $e_{i t}$ is time-varying and given by $\exp \left(\tilde{h}_{i t}\right)$. A GLS transformation involves dividing both sides of the equation by $\sqrt{\exp \left(\tilde{h}_{i t}\right)}$ to produce $v_{i t}^{*}=-\alpha v_{-i t}^{*}+e_{i t}^{*}$ where ${ }^{*}$ denotes the transformed variables and $\operatorname{var}\left(e_{i t}^{*}\right)=1$. The conditional posterior for $\alpha$ is normal with mean and variance given by $M^{*}$ and $V^{*}$ :

$$
\begin{aligned}
M^{*} & =\left(V\left(\hat{a}^{o l s}\right)^{-1}+v_{-i t}^{* \prime} v_{-i t}^{*}\right)^{-1}\left(V\left(\hat{a}^{o l s}\right)^{-1} \hat{a}^{o l s}+v_{-i t}^{* \prime} v_{i t}^{*}\right) \\
V^{*} & =\left(V\left(\hat{a}^{o l s}\right)^{-1}+v_{-i t}^{* \prime} v_{-i t}^{*}\right)^{-1}
\end{aligned}
$$

\section{A.2.3 Elements of $H_{t}$}

Conditional on the VAR coefficients and the parameters of the transition equation, the model has a multivariate non-linear state-space representation. Note that, the presence of lagged pre-determined variables in the transition equation 33, the constant term is time-varying. 
Carlin et al. (1992) show that the conditional distribution of the state variables in a general state-space model can be written as the product of three terms:

$$
\tilde{h}_{t} \backslash Z_{t}, \Xi \propto f\left(\tilde{h}_{t} \backslash \tilde{h}_{t-1}\right) \times f\left(\tilde{h}_{t+1} \backslash \tilde{h}_{t}\right) \times f\left(Z_{t} \backslash \tilde{h}_{t}, \Xi\right)
$$

where $\Xi$ denotes all other parameters. In the context of stochastic volatility models, Jacquier et al. (1994) show that this density is a product of log normal densities for $\bar{h}_{t}$ and $\bar{h}_{t+1}$ and a normal density for $Z_{t}$ where $\bar{h}_{t}=\exp \left(\tilde{h}_{t}\right)$. Carlin et al. (1992) derive the general form of the mean and variance of the underlying normal density for $f\left(\tilde{h}_{t} \backslash \tilde{h}_{t-1}, \tilde{h}_{t+1}, \Xi\right) \propto f\left(\tilde{h}_{t} \backslash \tilde{h}_{t-1}\right) \times$ $f\left(\tilde{h}_{t+1} \backslash \tilde{h}_{t}\right)$ and show that this is given as

$$
f\left(\tilde{h}_{t} \backslash \tilde{h}_{t-1}, \tilde{h}_{t+1}, \Xi\right) \sim N\left(B_{2 t} b_{2 t}, B_{2 t}\right)
$$

where $B_{2 t}^{-1}=Q^{-1}+F^{\prime} Q^{-1} F$ and $b_{2 t}=\tilde{h}_{t-1} F^{\prime} Q^{-1}+\tilde{h}_{t+1} Q^{-1} F$. Note that due to the non-linearity of the observation equation of the model an analytical expression for the complete conditional $\tilde{h}_{t} \backslash Z_{t}, \Xi$ is unavailable and a metropolis step is required. Following Jacquier et al. (1994) we draw from 35 using a date-by-date independence metropolis step using the density in 36 as the candidate generating density. This choice implies that the acceptance probability is given by the ratio of the conditional likelihood $f\left(Z_{t} \backslash \tilde{h}_{t}, \Xi\right)$ at the old and the new draw. To implement the algorithm we begin with an initial estimate of $\tilde{h}$ defined as $\left(\Delta Z_{t}\right)^{2}+0.00001$ where the offset constant 0.00001 is added to ensure positive volatility. We set the matrix $\tilde{h}^{\text {old }}$ equal to the initial volatility estimate. Then at each date the following two steps are implemented:

1. Draw a candidate for the volatility $\tilde{h}_{t}^{\text {new }}$ using the density 35 where $b_{2 t}=\tilde{h}_{t-1}^{\text {new }} F^{\prime} Q^{-1}+$ $\tilde{h}_{t+1}^{\text {old }} Q^{-1} F$ and $B_{2 t}^{-1}=Q^{-1}+F^{\prime} Q^{-1} F$

2. Update $\tilde{h}_{t}^{\text {old }}=\tilde{h}_{t}^{\text {new }}$ with acceptance probability $\frac{f\left(Z_{t} \backslash \tilde{h}_{t}^{\text {new }}, \Xi\right)}{f\left(Z_{t} \backslash \tilde{h}_{t}^{\text {old }}, \Xi\right)}$ where $f\left(Z_{t} \backslash \tilde{h}_{t}, \Xi\right)$ is the likelihood of the VAR for observation $t$ and defined as $\left|\Omega_{t}\right|^{-0.5}-0.5 \exp \left(\tilde{e}_{t} \Omega_{t}^{-1} \tilde{e}_{t}^{\prime}\right)$ where $\tilde{e}_{t}=Z_{t}-\left(c+\sum_{j=1}^{P} \beta_{j} Z_{t-j}\right)$ and $\Omega_{t}=A^{-1} H_{t} A^{-1^{\prime}}$

Repeating these steps for the entire time series delivers a draw of the stochastic volatilties.7.$^{7}$

\section{A.2.4 Parameters of the transition equation}

Conditional on the draw for the volatilities, the conditional posterior for $\bar{B}=\operatorname{vec}\left(\left[\alpha, \theta, d_{1}, . . d_{j}\right]\right)$ the parameters of the VAR in equation 32 is Normal. Letting $y$ and $x$ denote the left and the right hand side of the VAR in 32 , the conditional posterior of the coefficients is defined as

$$
G(\bar{B} \backslash \Xi)^{\sim} N\left(B^{*}, Q \otimes\left(x^{* \prime} x^{*}\right)^{-1}\right)
$$

\footnotetext{
${ }^{7}$ In order to take endpoints into account, the algorithm is modified slightly for the initial condition and the last observation. Details of these changes can be found in Jacquier et al. (1994).
} 
where $B^{*}=\left(x^{* \prime} x^{*}\right)^{-1}\left(x^{* \prime} y^{*}\right)$ and $x^{*}$ and $y^{*}$ denote $x$ and $y$ appended with dummy observations.

The conditional posterior for $Q$ is inverse Wishart and is given by

$$
G(Q \backslash \Xi)^{\sim} I W\left(S^{*}, T^{*}\right)
$$

where $T^{*}$ denote the number of actual observations plus the number of dummy observations and $S^{*}=\left(y^{*}-x^{*} b^{*}\right)^{\prime}\left(y^{*}-x^{*} b^{*}\right)$

The MCMC algorithm is applied using 100,000 iterations discarding the first 95,000 as burn-in.

We conduct a small Monte-Carlo experiment to test the algorithm. We generate data from the following DGP

$$
\begin{aligned}
& \left(\begin{array}{l}
y_{1 t} \\
y_{2 t}
\end{array}\right)=\left(\begin{array}{cc}
0.5 & 0.2 \\
-0.2 & 0.5
\end{array}\right)\left(\begin{array}{l}
y_{1 t-1} \\
y_{2 t-1}
\end{array}\right)+\left(\begin{array}{cc}
1 & 0 \\
-1 & 1
\end{array}\right)^{-1}\left(\begin{array}{cc}
h_{1 t} & 0 \\
0 & h_{2 t}
\end{array}\right)^{1 / 2}\left(\begin{array}{l}
e_{1 t} \\
e_{2 t}
\end{array}\right) \\
& \left(\begin{array}{l}
\ln h_{1 t} \\
\ln h_{2 t}
\end{array}\right)=\left(\begin{array}{cc}
0.5 & -0.1 \\
-0.01 & 0.5
\end{array}\right)\left(\begin{array}{l}
\ln h_{1 t-1} \\
\ln h_{2 t-1}
\end{array}\right)+\left(\begin{array}{cc}
0.1 & 0.01 \\
-0.1 & -0.1
\end{array}\right)\left(\begin{array}{c}
y_{1 t-1} \\
y_{2 t-1}
\end{array}\right)+\left(\begin{array}{cc}
0.6 & -0.5 \\
-0.5 & 0.6
\end{array}\right)^{1 / 2}\left(\begin{array}{l}
v \\
v
\end{array}\right.
\end{aligned}
$$

where $e_{i t}, v_{i t} \sim N(0,1)$ for $i=1,2$. We generate 500 observations and discard the first 100 to remove the effect of initial conditions. The experiment is repeated 100 times. At each iteration we calculate the impulse response to the two level shocks using an MCMC run of 5000 iterations.

A comparison of the true and estimated responses in figure 7 shows that the true response lies within the 95th percentile obtained from the simulation. This shows that the algorithm provides a satisfactory performance.

\section{B Sensitivity Analysis}

Figure 8 presents the impulse responses from an extended model that allows feedback from the volatilities. In other words, the VAR equation is assumed to be

$$
Z_{t}=c+\sum_{j=1}^{P} \beta_{j} Z_{t-j}+\sum_{k=1}^{K} b_{k} \tilde{h}_{t-k}+\Omega_{t}^{1 / 2} e_{t}
$$

The policy shock is identified using the benchmark sign restrictions discussed in the main text. The results in figure 8 show that this extension does not have a big impact on the results-The monetary policy shock leads to an increase in the volatility of the endogenous variables.

Figure 9 shows that when the lag length $K$ in transition equation 33 is increased to 12 , the key results remain similar to the benchmark case. Finally in figure 10 we present results from a version of the model that replaces industrial production growth with the the unemployment rate. The monetary policy shock is identified by assuming that a contractionary shock that 


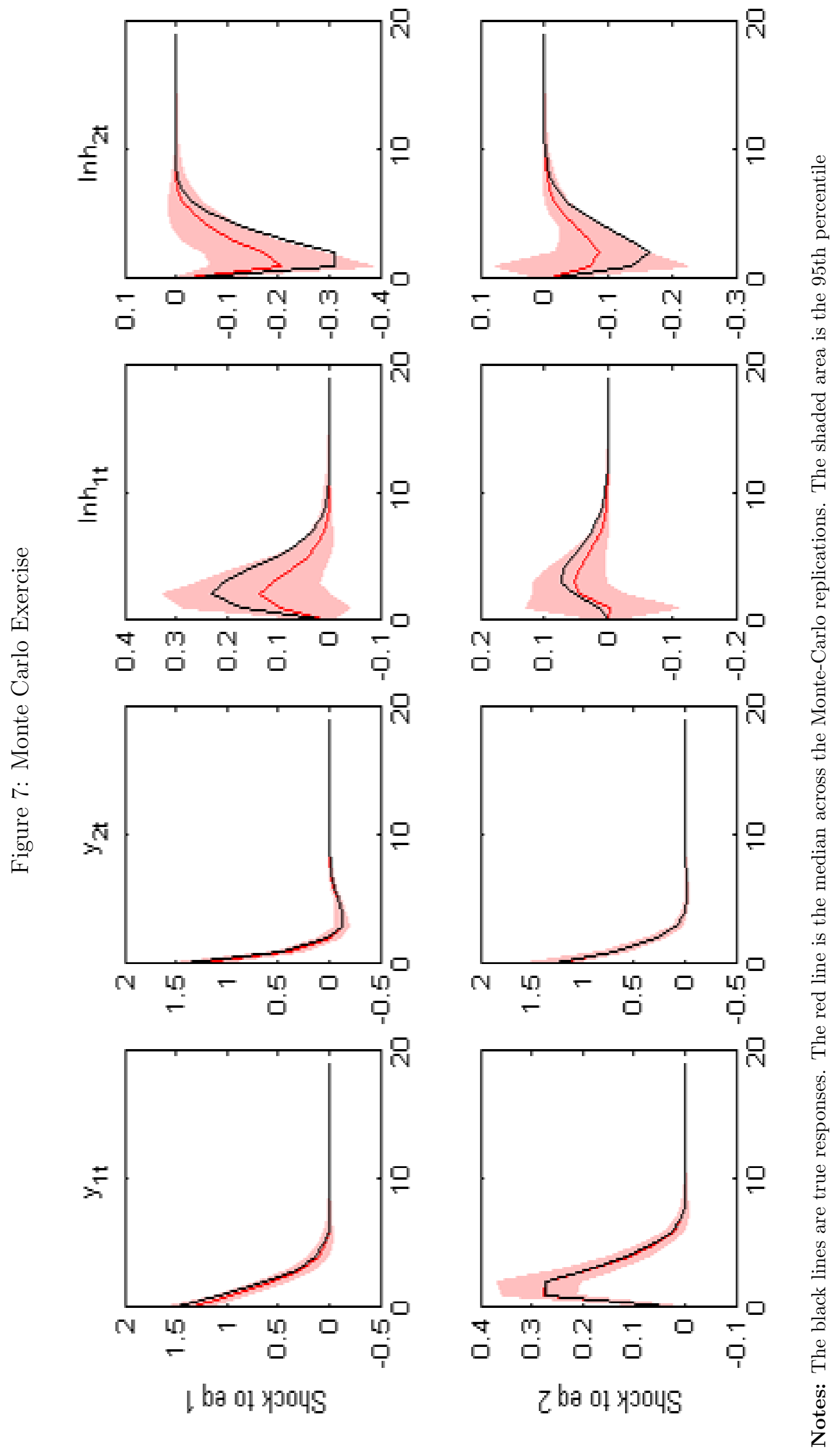




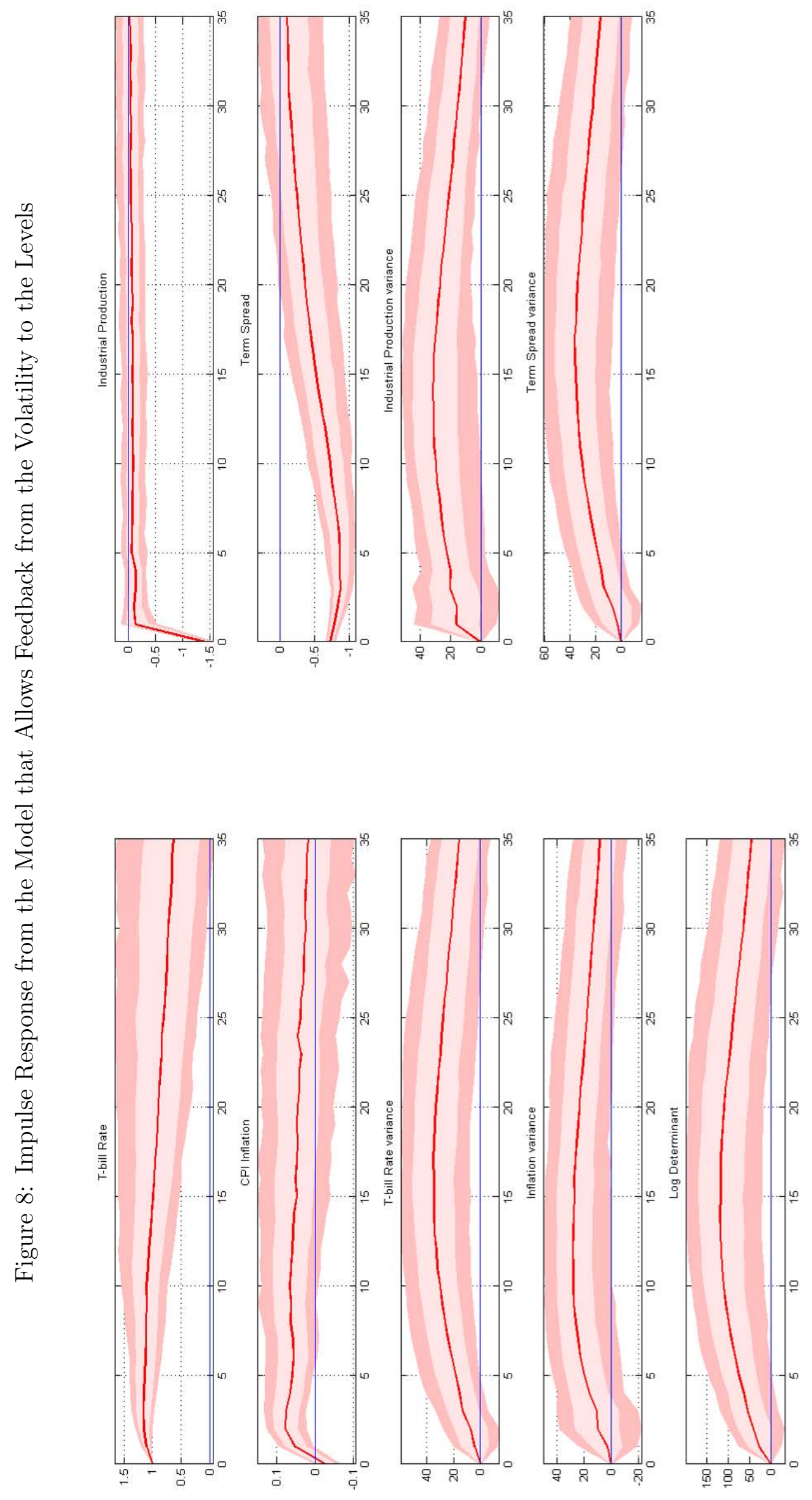




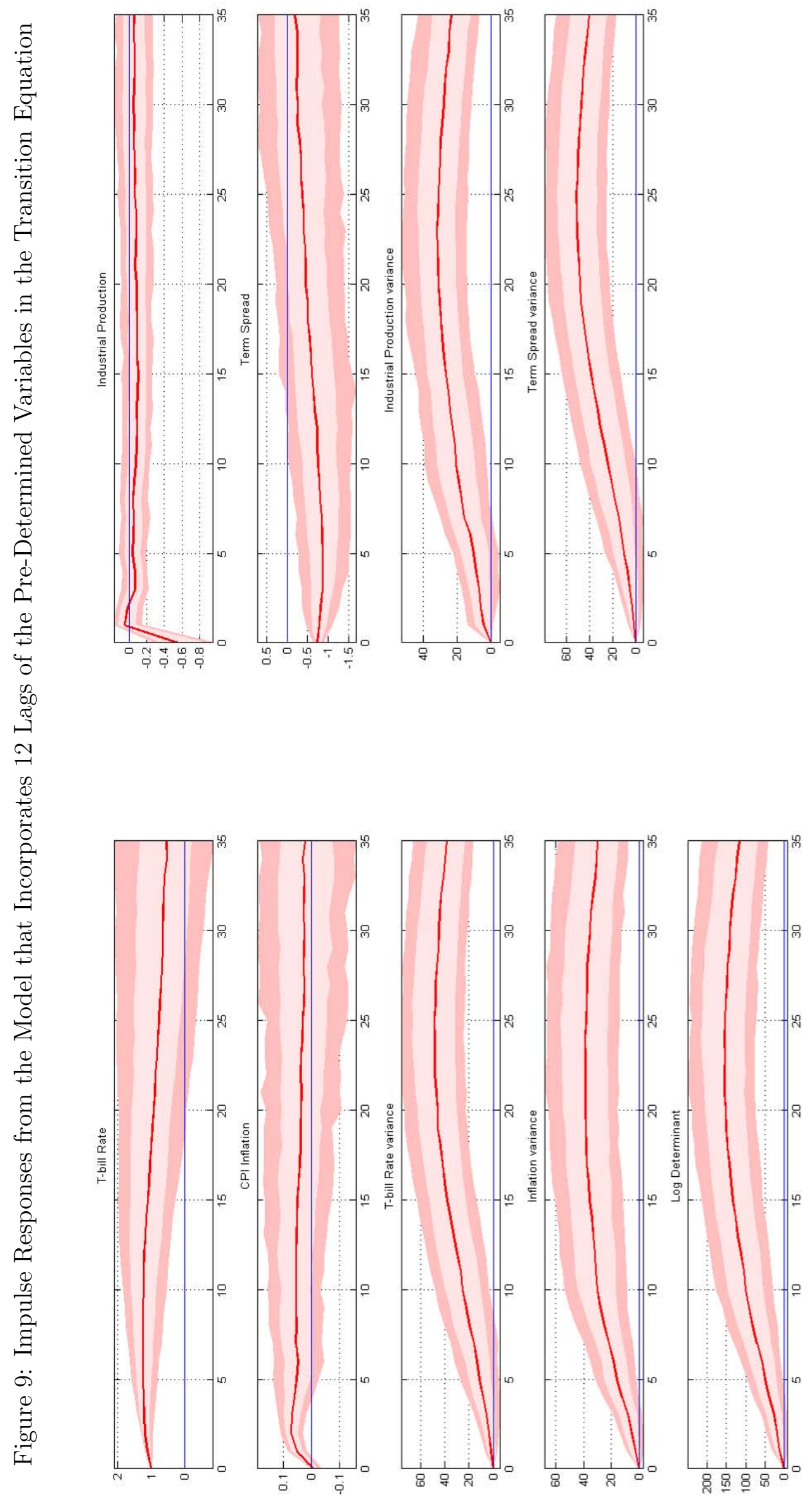




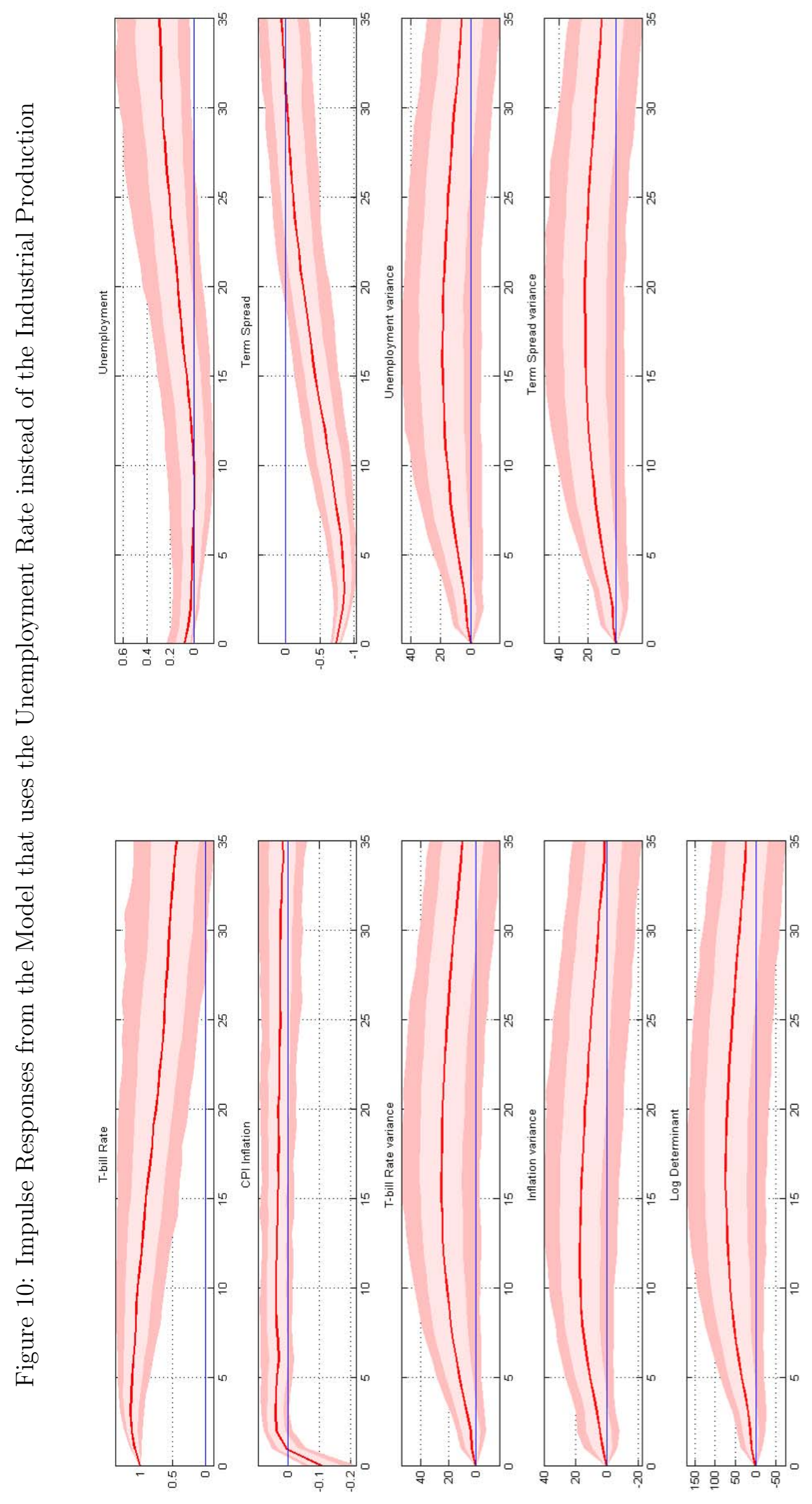




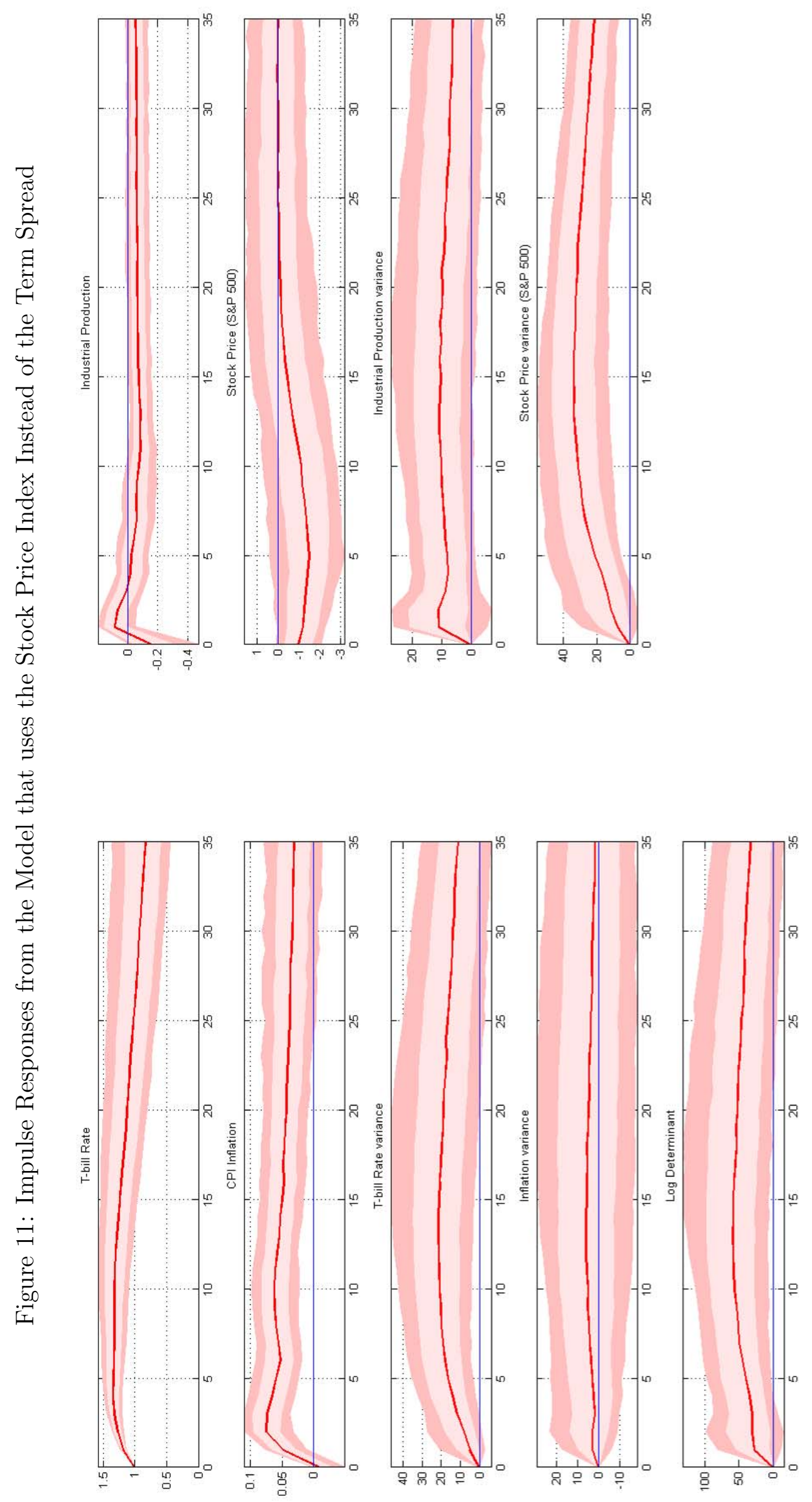


raises rates also leads to a rise in unemployment rate and a decrease in inflation on impact. The policy shock leads to an increase in the volatility of the endogenous variables, with the variance of the interest rates rising by a larger amount than inflation and unemployment variance. Figure 11 shows that the main results are preserved when the (de-trended) stock index is added to the model in place of the term spread 


\section{DSGE Model Analysis}

\section{C.1 Stationary Equations}

$$
\begin{aligned}
& u\left(C_{t}, L_{t}\right)=\frac{C_{t}^{1-\sigma_{C}}}{1-\sigma_{C}}-\chi_{0} \frac{L_{t}^{1+\sigma_{L}}}{1+\sigma_{L}} \\
& \breve{V}_{t} \equiv E_{t}\left(V_{t+1} \Gamma_{t+1}^{1-\sigma_{C}}\right)^{1-\gamma} \\
& \dddot{V}_{t} \equiv \breve{V}_{t}^{\frac{1}{1-\gamma}} \\
& V_{t}=u\left(C_{t}, L_{t}\right)+\beta \dddot{V}_{t} \\
& \chi_{0} L_{t}^{\sigma_{L}} C_{t}^{\sigma_{C}}=W_{t} \\
& M_{t+1}=\left[\frac{V_{t+1}}{\dddot{V}_{t}} \Gamma_{t+1}^{1-\sigma_{C}}\right]^{-\gamma}\left(\frac{C_{t}}{C_{t+1} \Gamma_{t+1}}\right)^{\sigma_{C}} \\
& \frac{1}{R_{t}^{A}}=\beta E_{t} \frac{M_{t+1}}{\Pi_{t+1}} \\
& Y_{t}=\bar{K}^{\phi} L_{t}^{1-\phi} \\
& M C_{t}=\frac{W_{t} L_{t}}{(1-\phi) Y_{t}^{d}} \\
& K_{P, t}=M C_{t} Y_{t}^{d}+\beta \xi E_{t} M_{t+1} \Pi_{t+1}^{\varepsilon} K_{P, t+1} \Gamma_{t+1} \\
& F_{P, t}=Y_{t}^{d}+\beta \xi E_{t} M_{t+1} \Pi_{t+1}^{\varepsilon-1} F_{P, t+1} \Gamma_{t+1} \\
& \bar{\Pi}_{t}=\frac{\varepsilon}{\varepsilon-1} \frac{K_{P, t}}{F_{P, t}} \\
& 1=\xi \Pi_{t+1}^{\varepsilon-1}+(1-\xi) \bar{\Pi}_{t}^{1-\varepsilon} \\
& \Delta_{t}^{\frac{1}{1-\phi}}=(1-\xi) \bar{\Pi}_{t}^{-\frac{\varepsilon}{1-\phi}}+\xi \Pi_{t}^{\frac{\varepsilon}{1-\phi}} \Delta_{t-1}^{\frac{1}{1-\phi}} \\
& Y_{t}^{d}=C_{H, t}+G_{t} \\
& Y_{t}=\Delta_{t} Y_{t}^{d}
\end{aligned}
$$




\section{C.2 Steady States}

We assume that $L=1 / 3$ and $Y=1$ and we derive the steady-state of capital from the production function

$$
K^{\phi}=\left(\frac{Y}{L^{1-\phi}}\right)^{\frac{1}{\phi}}
$$

From the stoschastic discount factor we obtain

$$
M=\Gamma^{-\sigma_{C}}
$$

From the PP equations we obtain

$$
\begin{aligned}
K_{P} & =\frac{M C Y^{d}}{1-\beta \xi \Pi^{\varepsilon} \Gamma^{1-\sigma_{C}}} \\
F_{P} & =\frac{Y^{d}}{1-\beta \xi \Pi^{\varepsilon-1} \Gamma^{1-\sigma_{C}}} \\
\bar{\Pi}= & \left(\frac{1-\xi \Pi^{\varepsilon-1}}{1-\xi}\right)^{\frac{1}{1-\varepsilon}} \\
\bar{\Pi} & =\frac{\varepsilon}{\varepsilon-1} \frac{K}{F}=\frac{\varepsilon}{\varepsilon-1} \frac{\frac{M C Y^{d}}{1-\beta \xi M \Pi^{\varepsilon}}}{\frac{Y^{d}}{1-\beta \xi M \Pi^{\varepsilon-1} \Gamma}} \\
\bar{\Pi} & =\frac{\varepsilon}{\varepsilon-1} \frac{1-\beta \xi \Pi^{\varepsilon-1} \Gamma^{1-\sigma_{C}}}{1-\beta \xi \Pi^{\varepsilon} \Gamma^{1-\sigma_{C}} M C} \\
M C & =\bar{\Pi} \frac{\varepsilon-1}{\varepsilon} \frac{1-\beta \xi \Pi^{\varepsilon} \Gamma^{1-\sigma_{C}}}{1-\beta \xi \Pi^{\varepsilon-1} \Gamma^{1-\sigma_{C}}} \\
M C & =\frac{\varepsilon-1}{\varepsilon}\left(\frac{1-\xi \Pi^{\varepsilon-1}}{1-\xi}\right)^{\frac{1}{1-\varepsilon}} \frac{1-\beta \xi \Pi^{\varepsilon} \Gamma^{1-\sigma_{C}}}{1-\beta \xi \Pi^{\varepsilon-1} \Gamma^{1-\sigma_{C}}}
\end{aligned}
$$

Then from the price dispersion equation

$$
\Delta=\left(\frac{(1-\xi) \bar{\Pi}^{-\frac{\varepsilon}{1-\phi}}}{1-\xi \Pi^{\frac{\varepsilon}{1-\phi}}}\right)^{1-\phi}
$$

From the marketing clearing condition we also know that

$$
Y^{d}=\frac{Y}{\Delta}
$$

Similarly

$$
C=(1-g) Y^{d}
$$


From the demand for labour

$$
W=\frac{M C(1-\phi) Y^{d}}{L}
$$

From the labour supply

$$
\chi_{0}=\frac{W}{L^{\sigma_{L}} C^{\sigma_{C}}}
$$

